\title{
الملك الأشرف خليل بن قلاوون ودوره في أنهاء الوجود الصليبي في بلاد الثام (689-693هـ/ 1290-
} (1294

غازي عبدالله سليمان الشقيرات

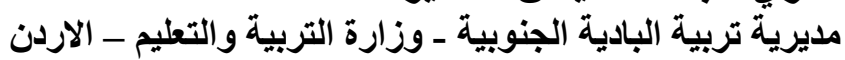
الايميل: Ghazzi48@yahoo.com

الملخص

تعتبر فترة حكم الملك الاشرف خليل بن قلاوون من الفترات الحاسمة في تاريخ المماليك خاصة وتاريخ الأمة الإسلامية عامة، حتى اعثبرت في نظر كثير من المؤرخين بأنها مرحلة العصر الذهبي وعصر الازدهار، إذ

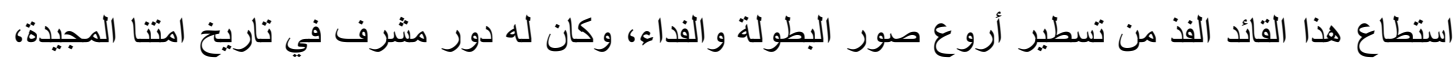
وفي التصدي للوجود الصليبي الذي كان مخيم على بلاد الثام، في وقت لم يستطيع قادة عظام من تحقيق ما حققه هذا البطل المغوار. حيث تناولت هذه الدر اسة فترة حكم الاشرف خليل بن قلاوون (689-693هـ/ 1290-1294م)، وهدفت هذه الدراسة على التعرف على أبرز ملامح شخصية السلطان الاشرف خليل، من حيث حياته ونشأته، وتوليه السلطنة، ثم تناولت هذه الدراسة اهم الاحداث البارزة والجوهرية في عهده والتي تتمثل بالمسير نحو عكا، وفرض الحصار عليها، ثم فتح مدينة عكا، ثم تم الحديث عن وفاته، من حيث المؤامرات التي دبرت وأحيكت ضده في الخفاء من اجل القضاء عليه، وكانت من المقربين اليه من نائبه ووزيره. 


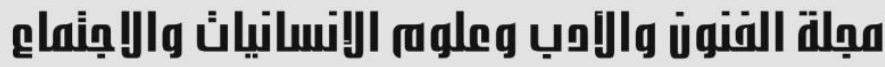 \\ Journal of Arts, Literature, Humanities and Social Sciences www.jalhss.com \\ Volume (53) June 2020 العدد (53) يونيو 2020
}

\section{The honorable king Khalil bin Qalawun and his Role in Ending the Crusader Presence in the Levant}

\author{
Ghazi Abdullah AL -Shouqairat \\ Southern Badia Education Directorate - Ministry of Education - Jordan \\ Email: ghazzi48@yahoo.com
}

\begin{abstract}
The period of the reign of King Khalil bin Qalawun is considered one of the decisive periods in the history of the Mamluks in particular and the history of the Islamic nation in general, until it was considered by many historians as the stage of the golden age and the age of prosperity, as this feat leader managed to underline the most magnificent images of heroism and redemption, and he had an honorable role In the history of our glorious nation, and in confronting the Crusader presence that was a camp on the Levant, at a time when great leaders were unable to achieve what the heroic hero achieved.

As this study dealt with the period of the rule of Al-Ashraf Khalil bin Qalawun (689-993 AH / 1290-1294 AD), this study aimed to identify the most prominent features of the personality of Sultan Al-Ashraf Khalil, in terms of his life and development, and his assumption of the Sultanate, then this study examined the most important and significant events in His reign, which is represented by the march towards Acre, and the imposition of the siege on it, then he opened the city of Acre, then it was talked about his death, in terms of the conspiracies that were orchestrated against him in secret in order to eliminate him, and they were close to him from his deputy and his minister.
\end{abstract}

Keywords: Al-Ashraf Khalil bin Qalawun, the Crusaders, the city of Acre, Bilad alSham. 


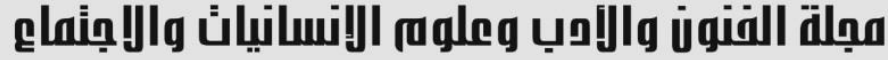

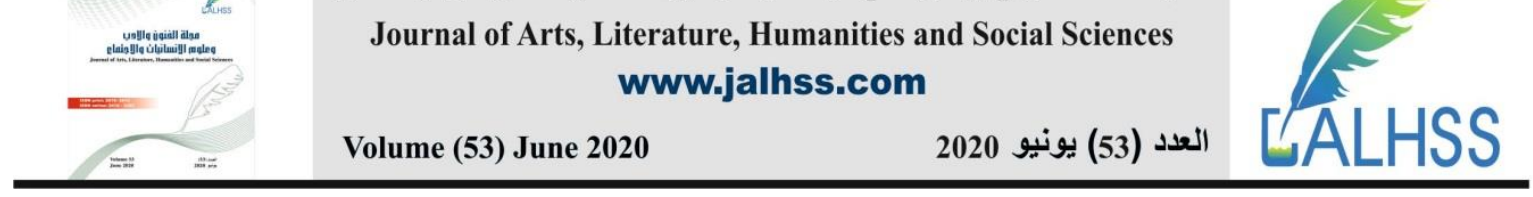

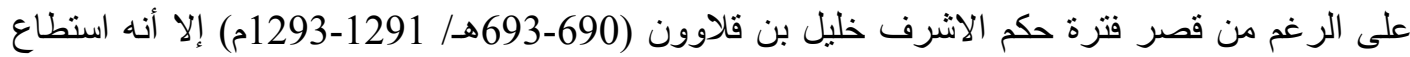

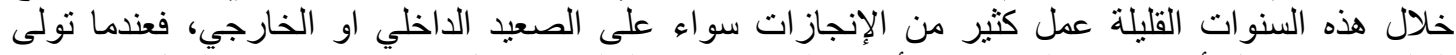

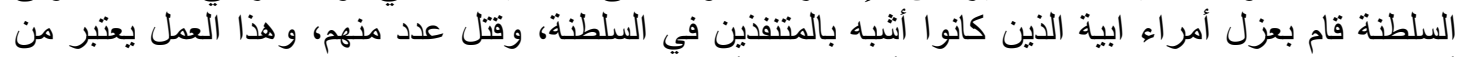

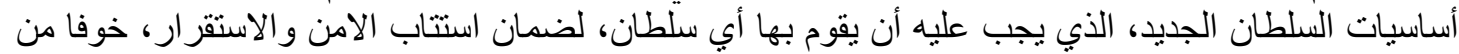

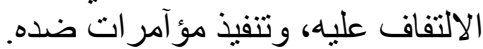

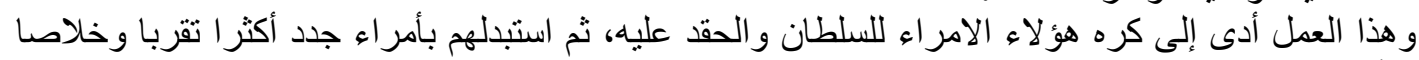

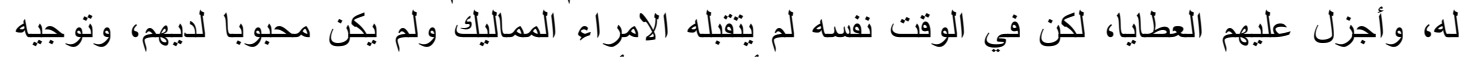

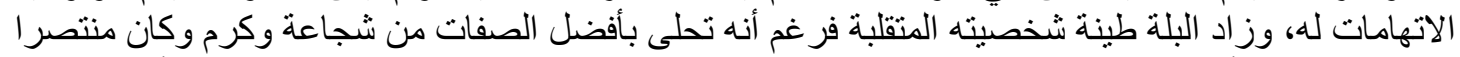

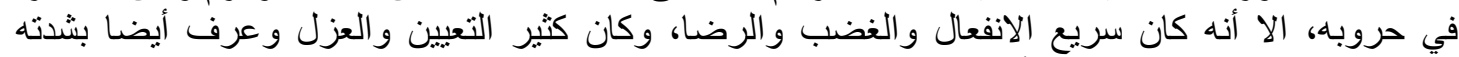

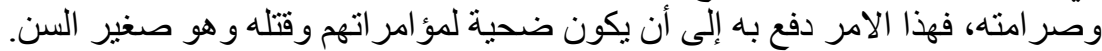

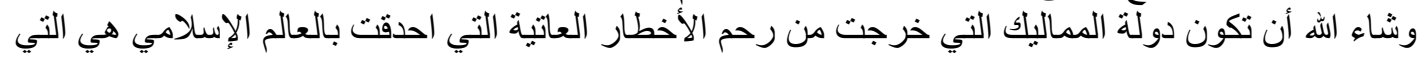

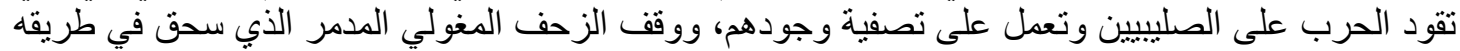

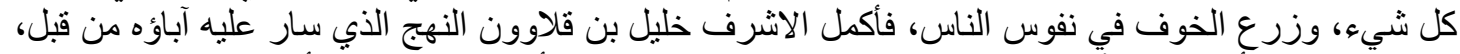

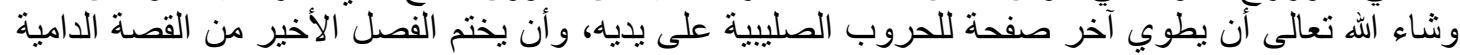

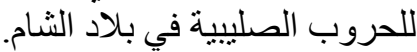

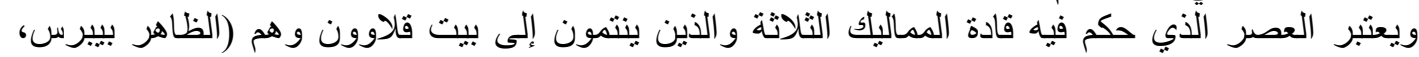

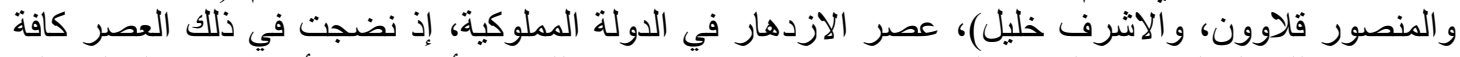

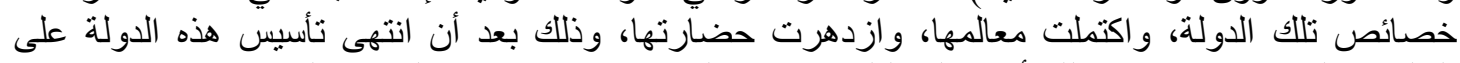

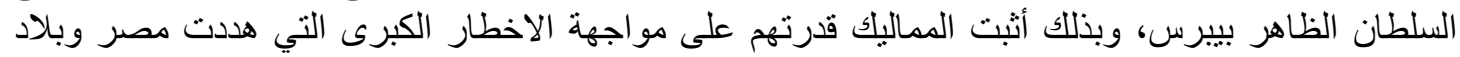

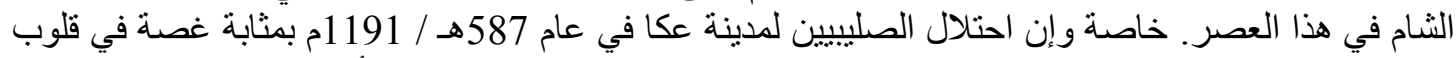

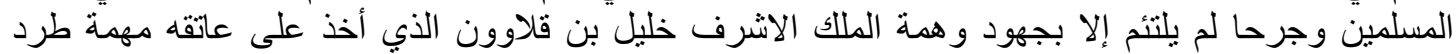
الصليبيين من الثشام نهائيا.

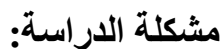
حاولت هذه الدراسة الوقوف على فترة حكم الاشرف خليل بن قلاوون من حيث حياته ونشأته وتوليه للسلطنة

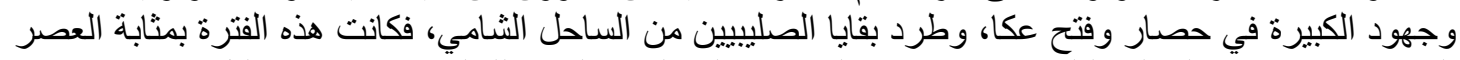

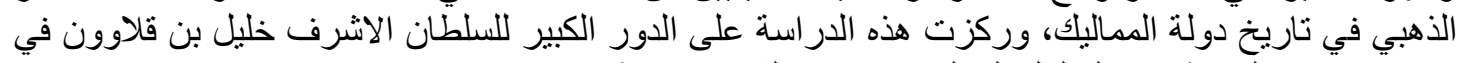

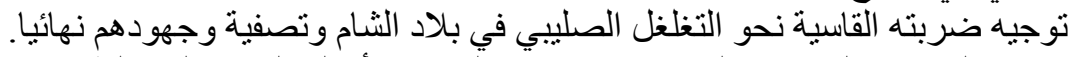

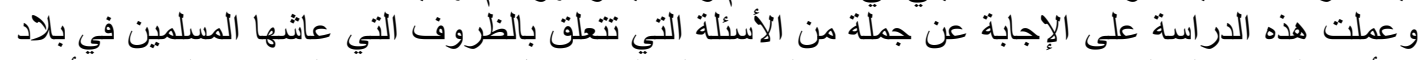

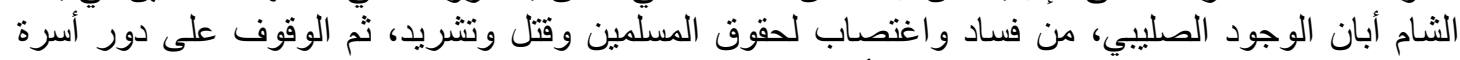

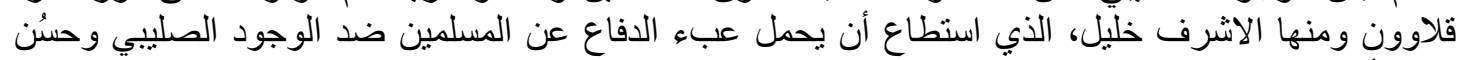

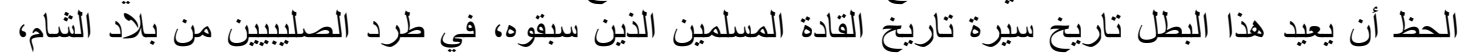
ليسطر نقطة مضيئة في سجل التاريخ تتناقلها الأجيال المتعاقبة.

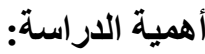
تكمن أهمية الدراسة في كونها قد بحثت في شخصية عريقة وقوية تنتمي إلى بيت قلاوون الهابة آلا وهي شخصية

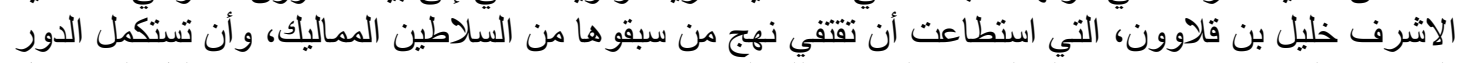

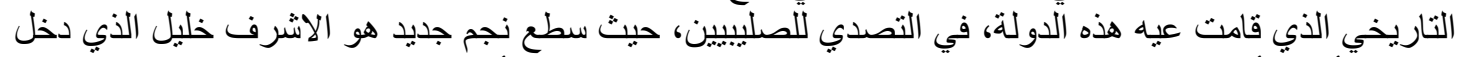

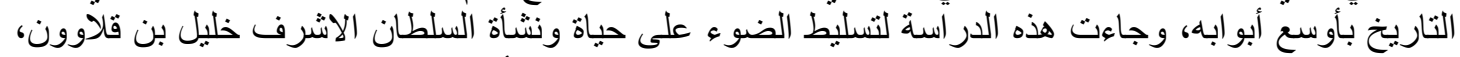

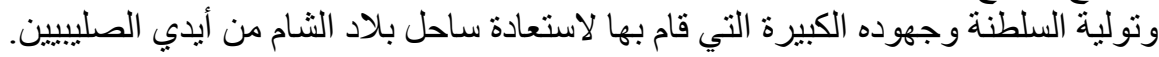




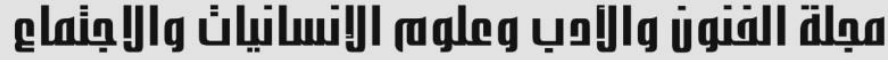

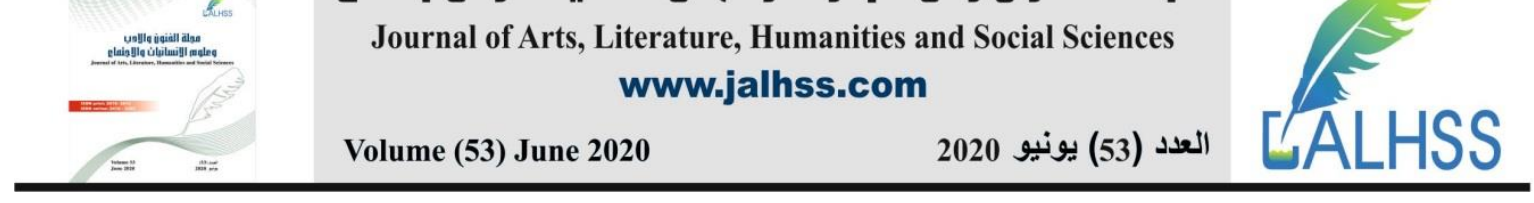

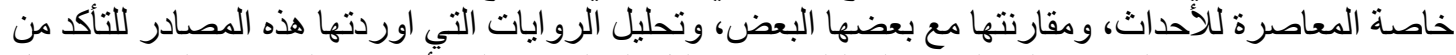

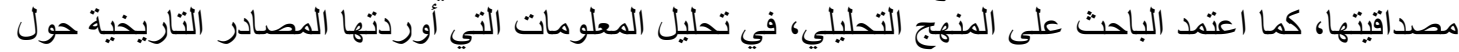
صفات الاشرف خليل بن قلاوون ومقتله، و الوصول إلى نقطة الالتقاء بينها.

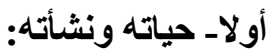

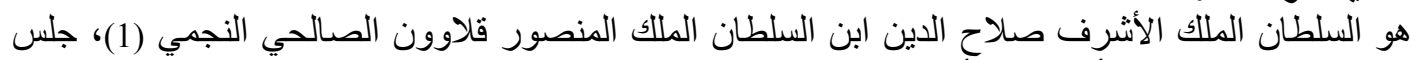

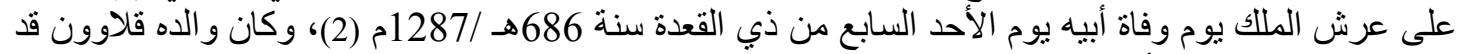

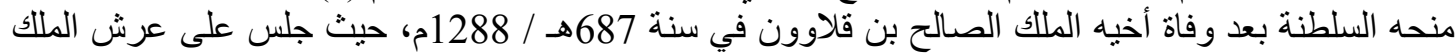

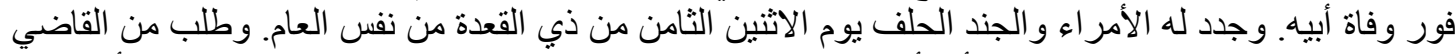

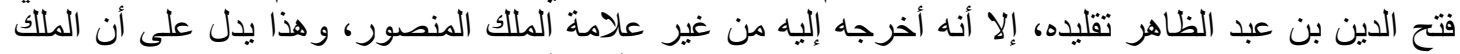

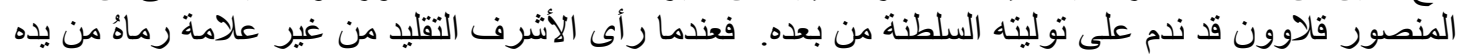

و هو الثامن من سلاطين المماليك البحرية في الثام ومصر (4)، استفتح بداية عهده بالجهاد، وذهب إلى على عكا

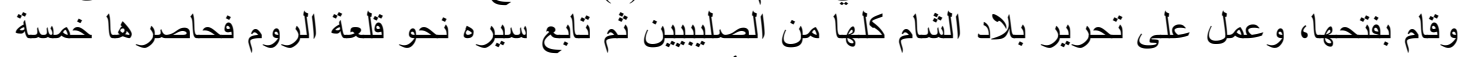

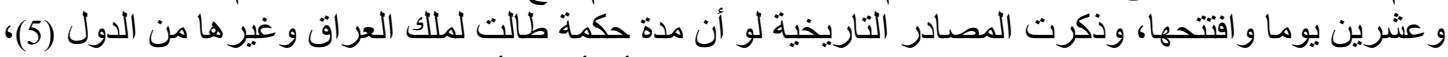

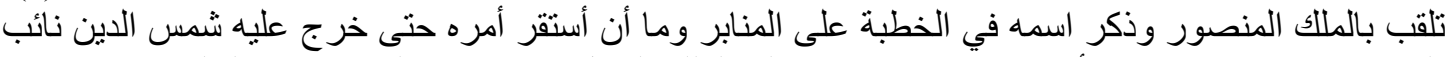

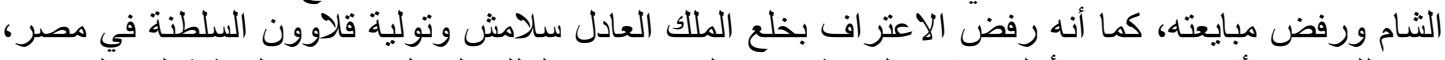

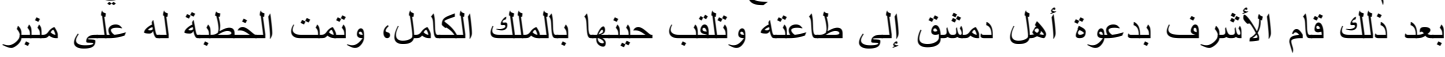

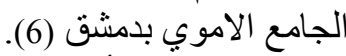

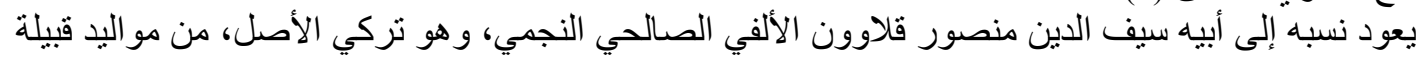

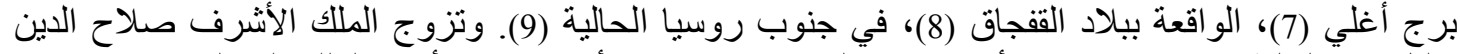

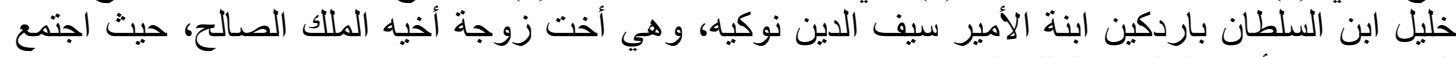

الناس في بيت أخيه السلطان الملك الصالح علاء (10).

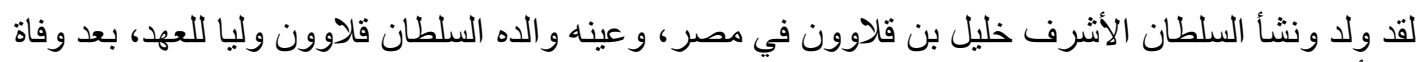

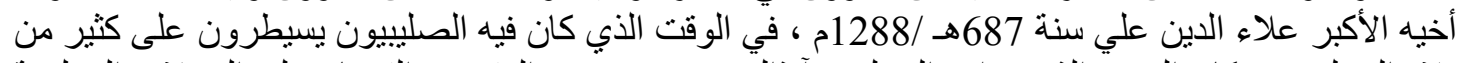

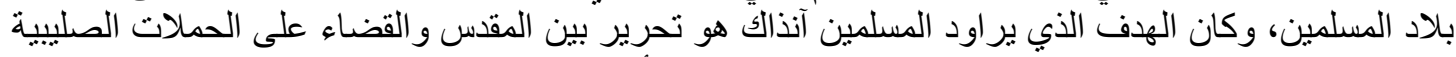

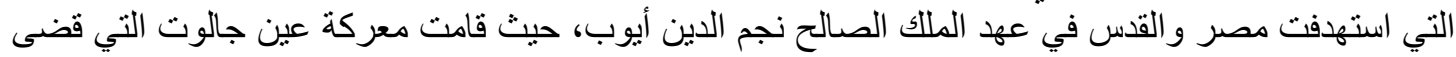

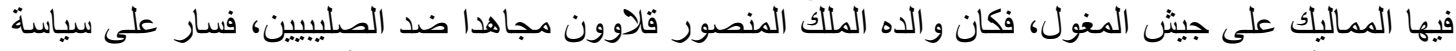

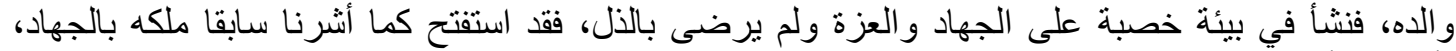

فأسنطاع أن يقطف ثمرة جهاده بالقضاء نهائيا على الوجود الصليبي في بلاد الثام (11).

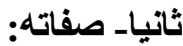

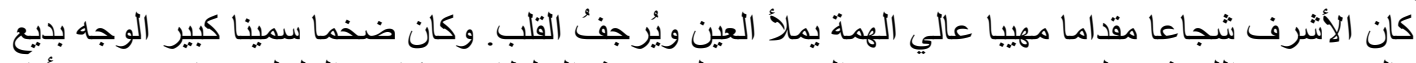

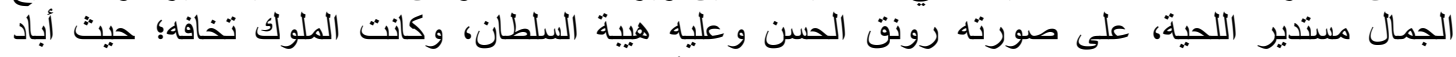

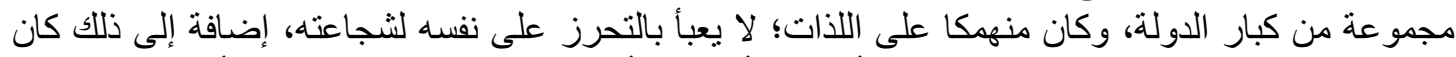

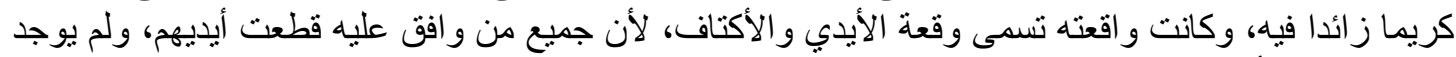
في فترة حكمه أية مظلمة (12).

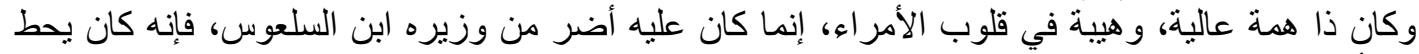

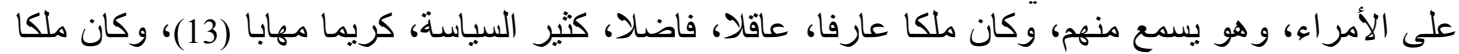




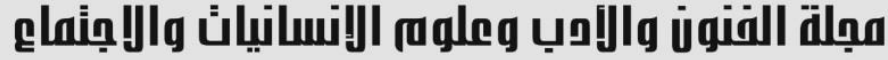

\section{Journal of Arts, Literature, Humanities and Social Sciences www.jalhss.com}

كريما شجاعا مقداما سريع الحركة مظفر ا في حروبه حيث فتح عكا وبيروت و غير ها (14)، وكان بطلا شجاعا ذا

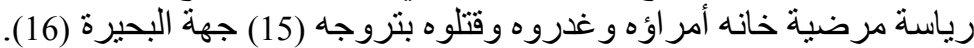

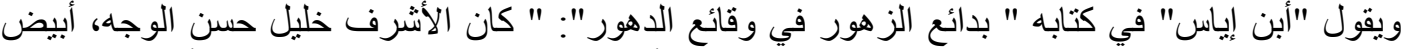

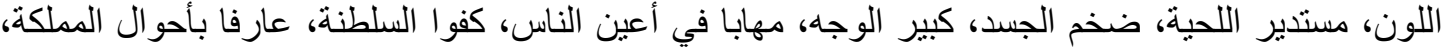

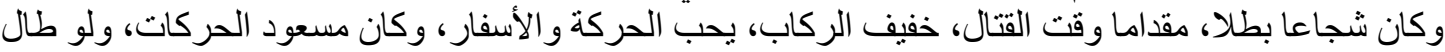
عمره، لقتح غالب بلاد العراق، و لا يعرف في أبناء الملوك من يناظره في شدة العزم و الثجاعة، وقوة البأس"

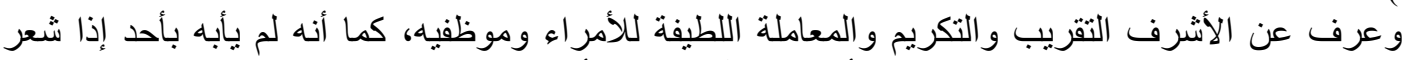

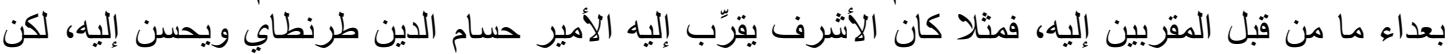

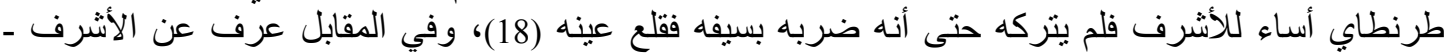

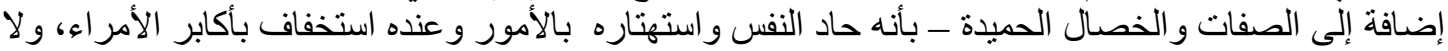

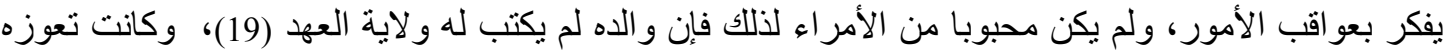
هيبة و الده وحكمه، و انغمس في نزو اتها وشهونه محنه للتعذيب (20).

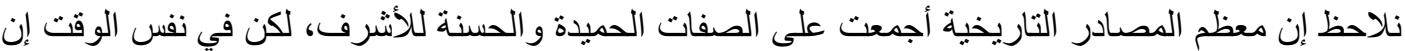

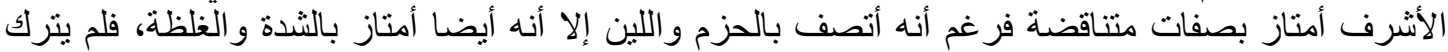

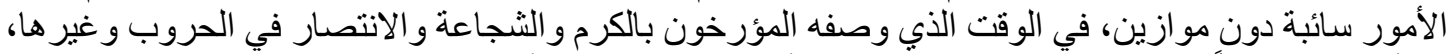

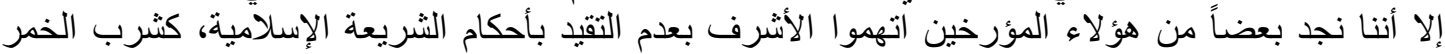

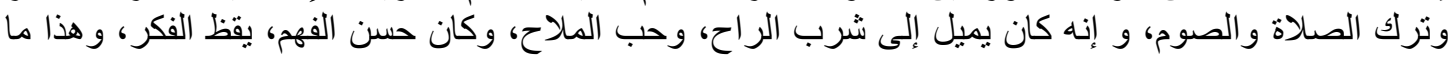

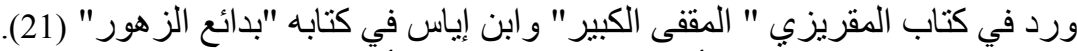

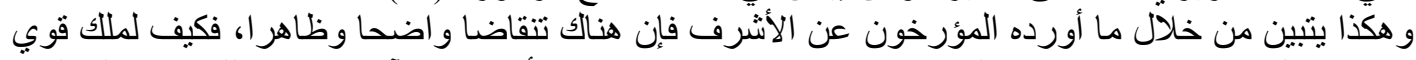

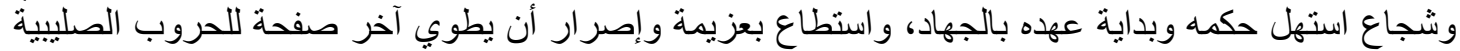
في بلاد الشام، وتصفية وجودهم بشكل نهائي بعد قرنين من الزمن، حتى لم يستطيع سلاطين المماليك الأقوياء

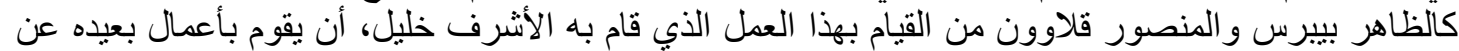
شخصيته كالانصر اف للملذات و الر احة، ففترة حكمه لا تتعدى ثنلاث سنوات قضاها في تحرير مدينة عكا و الساحل الثامي وقلعة الروم. و هناك دلائل تثير وتثبت أن الأشرف على عقد العزم على صوم شهر رمضان في دمشق، وامر بمنع العمل في

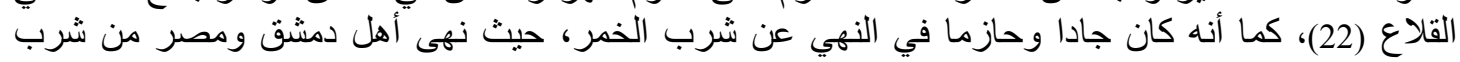

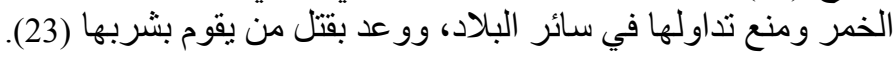

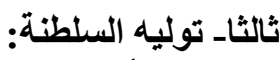

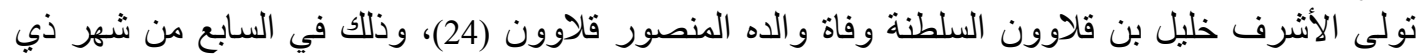

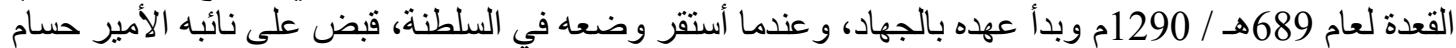
الدين طرنطاي، وذللك في الثاني عثر من ذي القعدة من العام نفسه، وفوض أوض نيابة السلطنة إلى بدر الدين بيدرا

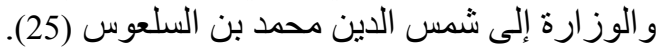
ولقد سار على سياسة أبيه الخارجية، فعقد العزم منذ تولية الحكم على محاربة الصليبيين، والعمل على طرد

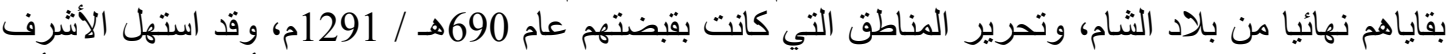

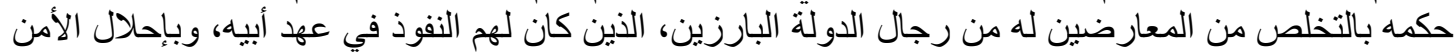

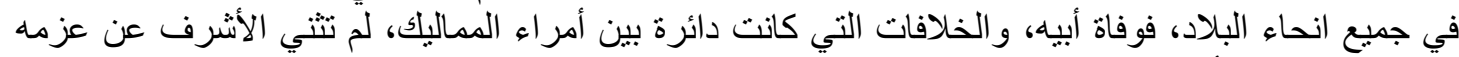

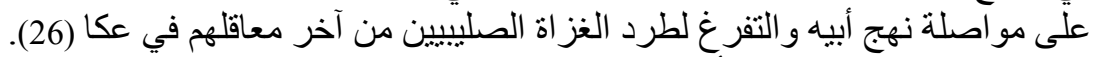

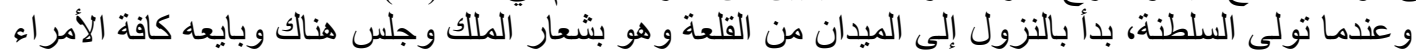

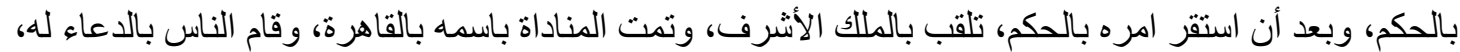
لا سيما و أنهم وجدو ا فيه خير التحرير البلاد من بقايا الصليبيين (27). 


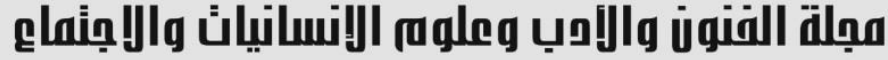

\author{
Journal of Arts, Literature, Humanities and Social Sciences \\ www.jalhss.com \\ Volume (53) June 2020 \\ العدد (53) يونيو 2020
}

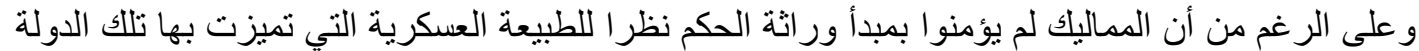

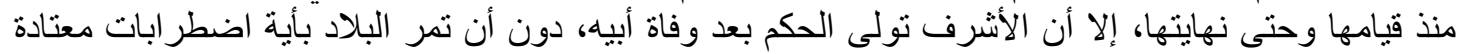

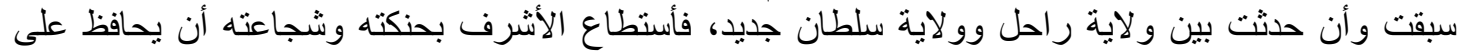

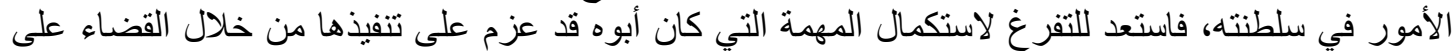
فلول الفرنجة في عكا (28).

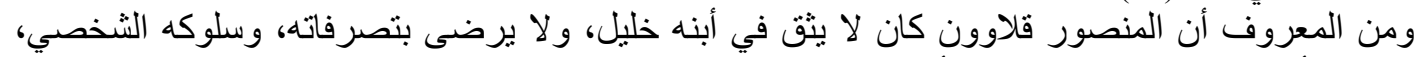

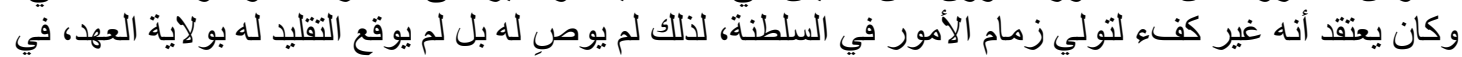

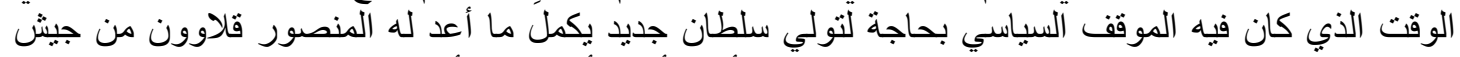

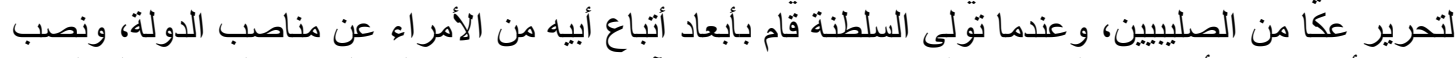

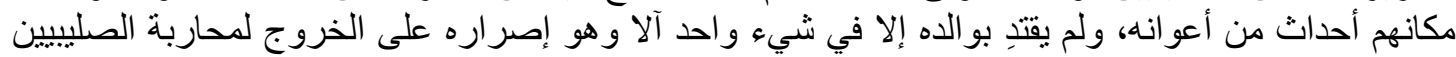
و و إخر اجهم من بلاد الثام (29).

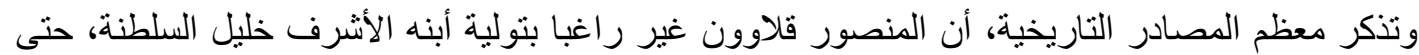

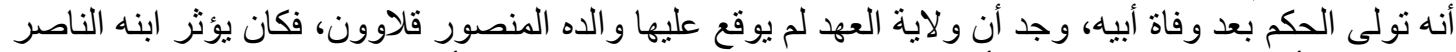

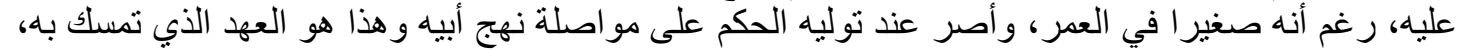

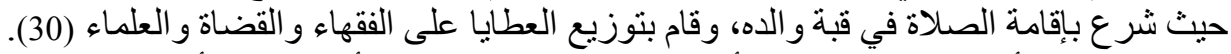

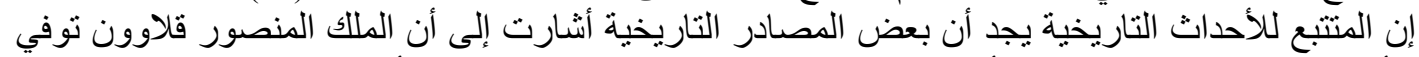

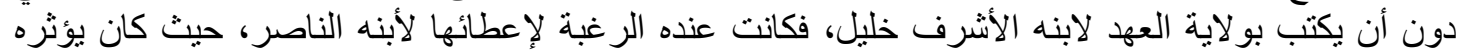

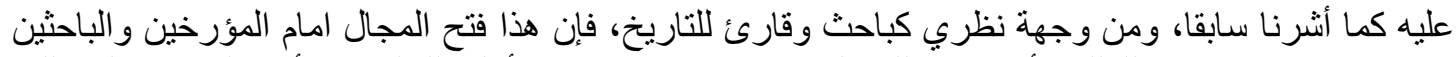

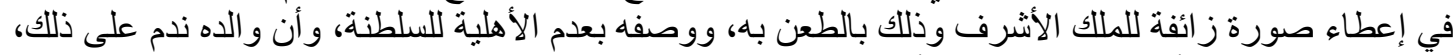

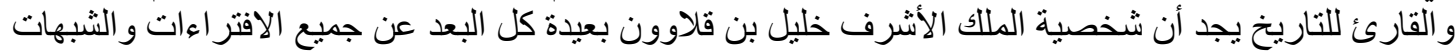

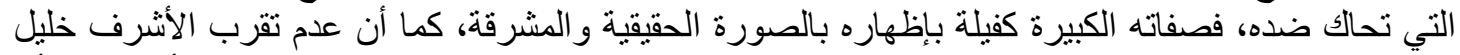

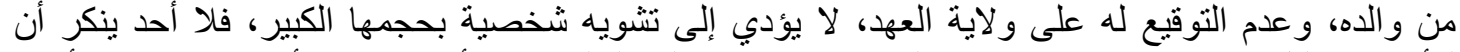

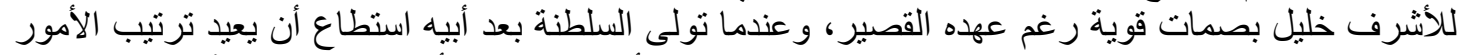

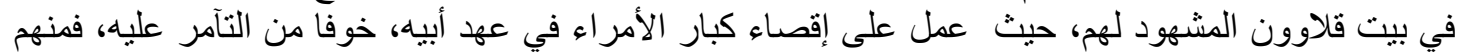

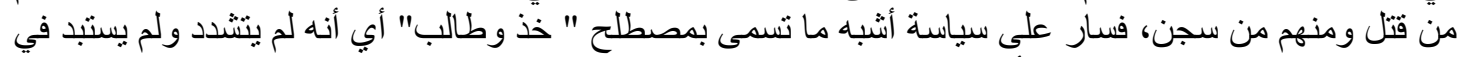
سلطته، وحقق إنجاز ات لم يحققها أحد من المماليك البحرية.

رابعا- استعدادات الأشرف وحصار مدينة عكا:

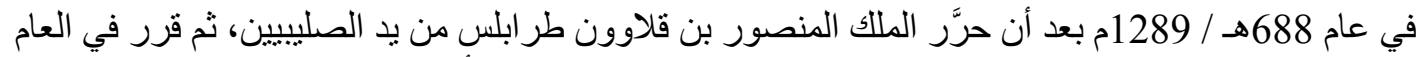

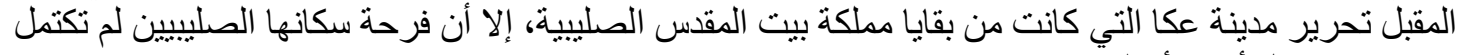
بسبب وفاته قبل أن يبدأ بالمسير نحو ها لتون (31).

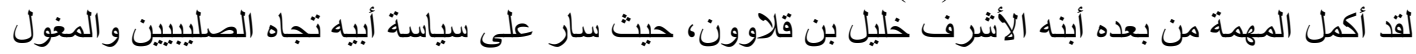

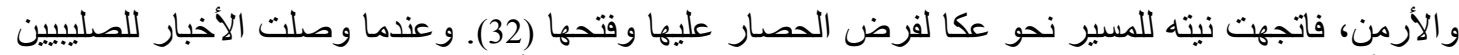

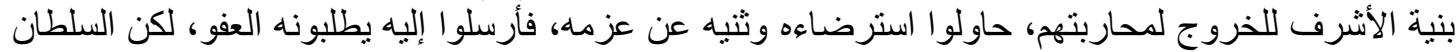

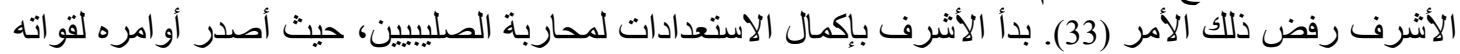

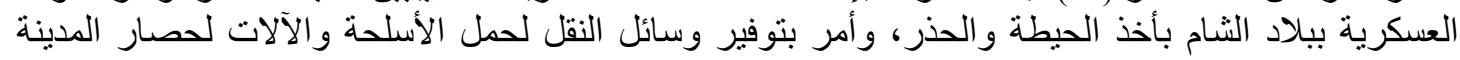

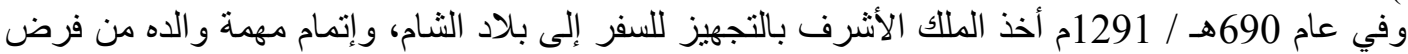

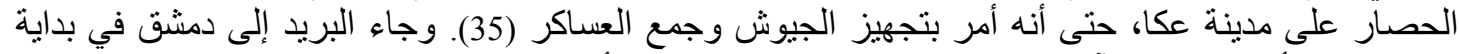

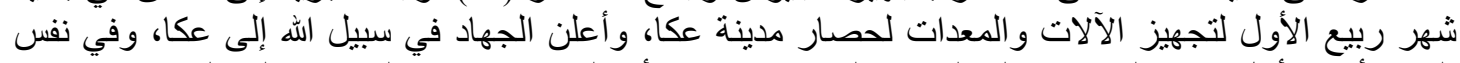

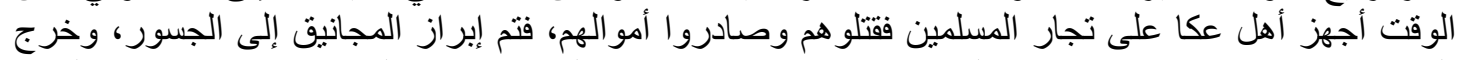

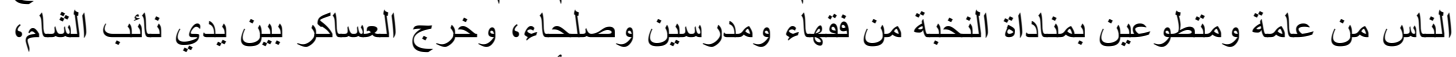

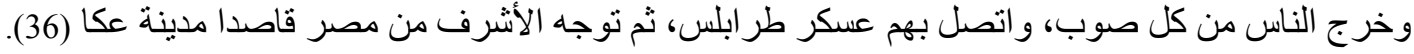




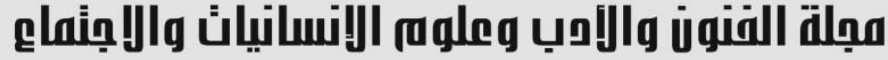

\author{
Journal of Arts, Literature, Humanities and Social Sciences \\ www.jalhss.com \\ Volume (53) June 2020 \\ العدد (53) يونيو 2020
}

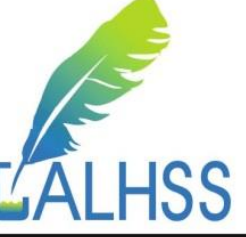

ووصل الأشرف أسوار مدينة عكا بعد مسيرة شهر تقريبا، وكان عدد معدات الحصار حوالي 92 منجنيقا

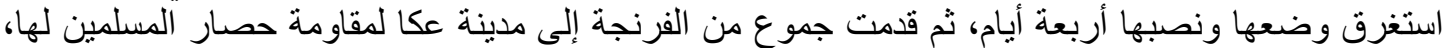

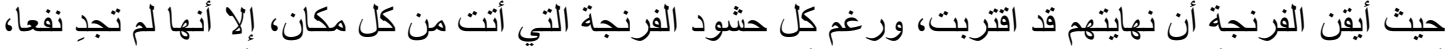

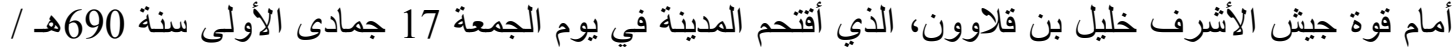

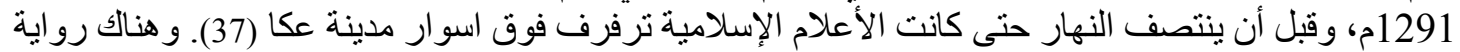

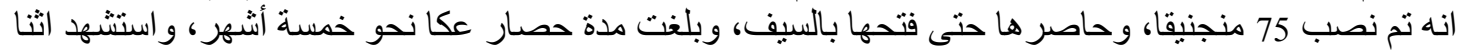

عشر أمير ا في فتحها، وقتل من المماليك السلطانية مائة و عشرون مملوكا (38).

خامسا- فتح مدينة عكا:

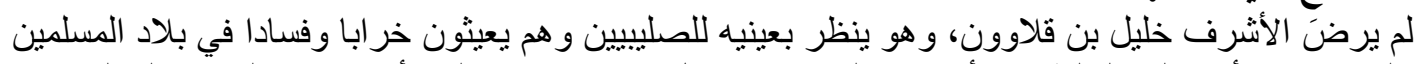

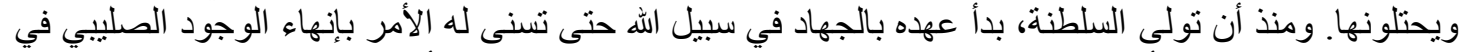

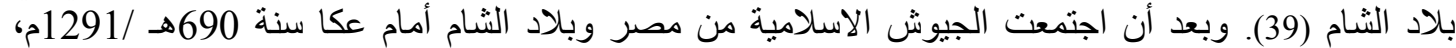

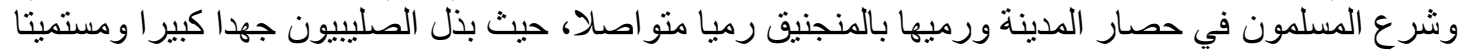

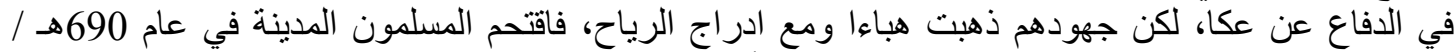

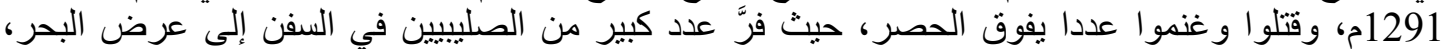

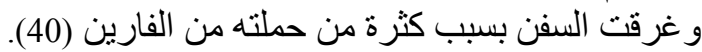
وما أن وصل جيش المسلمين بقيادة الأشرف خليل بليل بن قلاوون إلى المدينة حتى أخذت قو اتها في مهاجمة

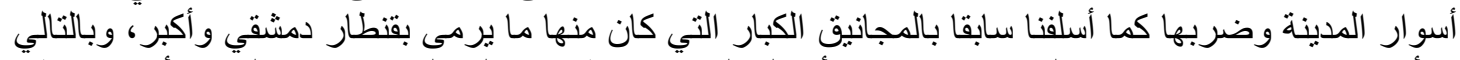

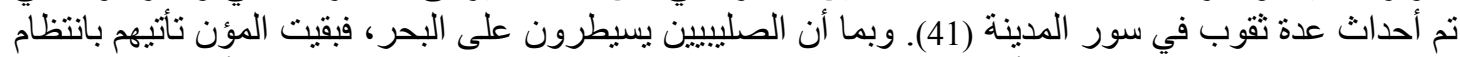

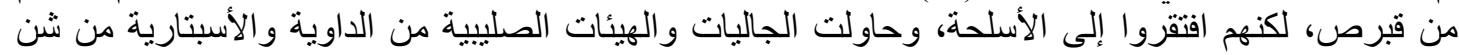

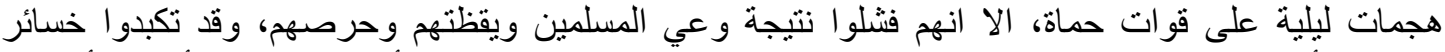

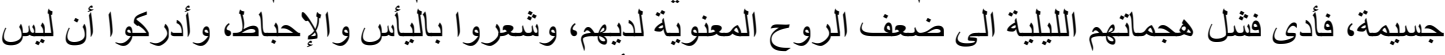

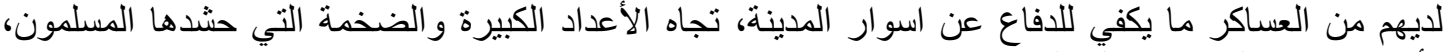

وأصبحت كفة النصر بيد المسلمين (42).

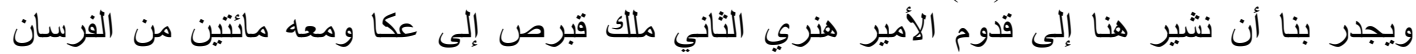

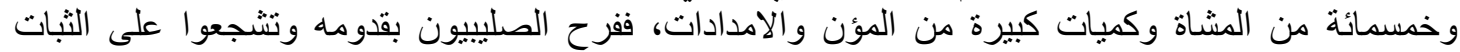

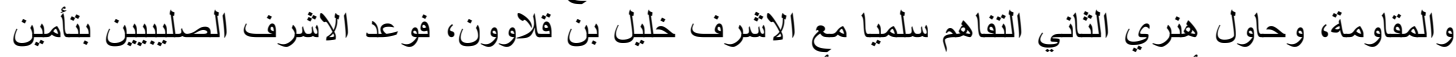

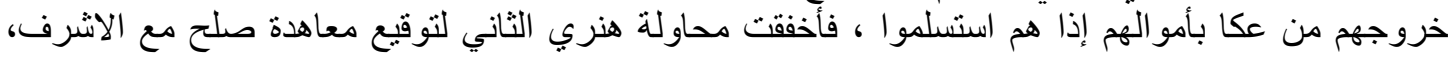

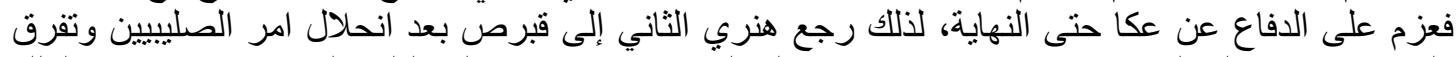

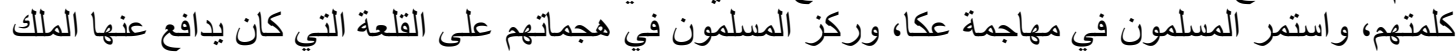

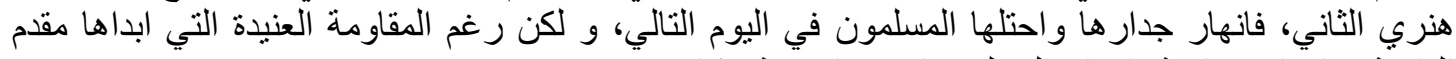

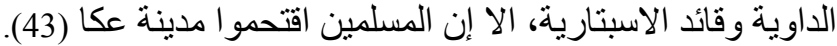

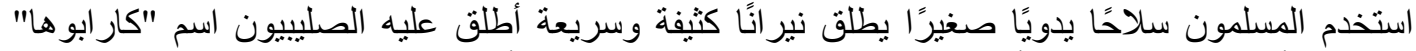

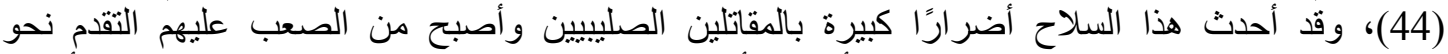

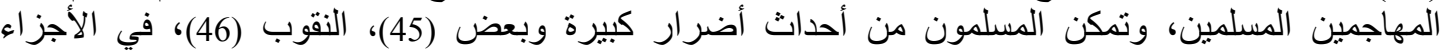

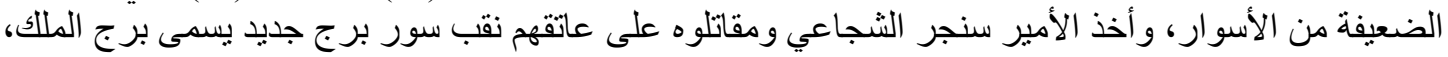

فقام الصليييون بإثعال النار فيه وتركوه ينهار (47).

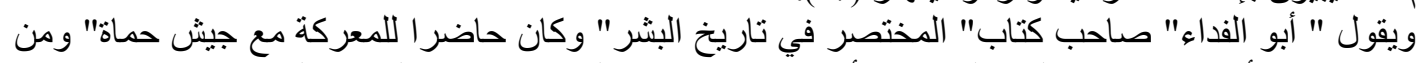

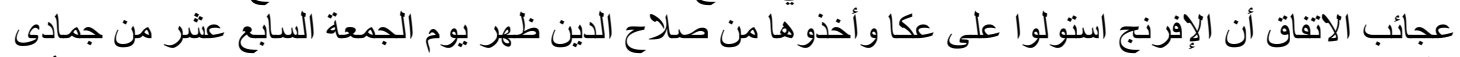

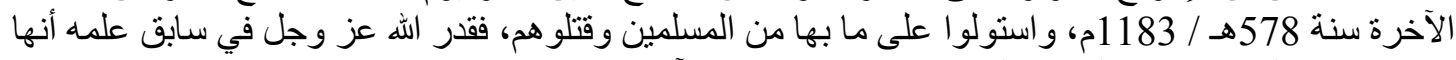

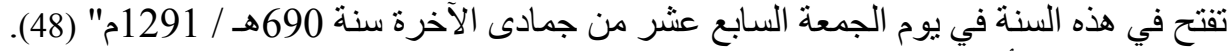

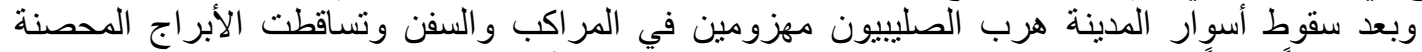

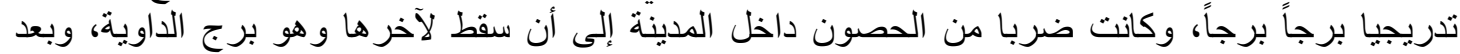

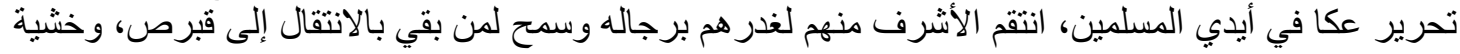




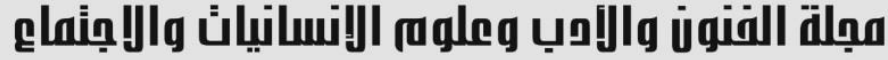

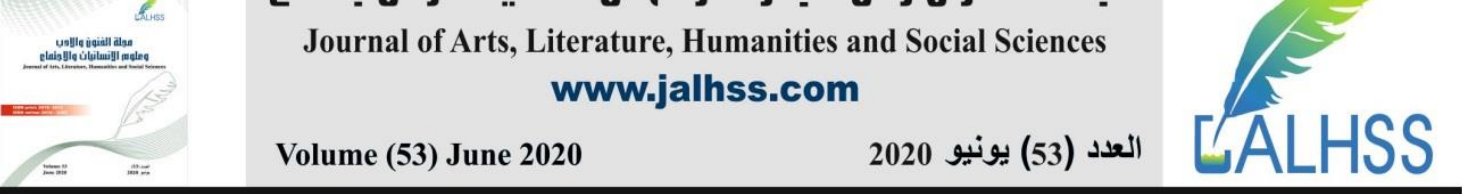

أن يفعل الصليبيون ما فعلوه بصلاح الدين الايوبي عام 587هـ/191م، ألأرسل أحد قادته إلى صور ليمنع

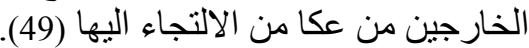
ولما فتح الملك الأشرف عكا، مدحه القاضي شهاب الدين محمود في قصيدته البائية المشهورة وهي (البسيط)

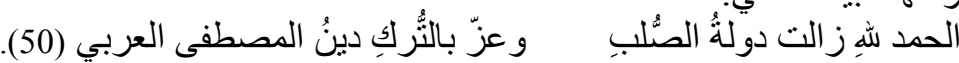

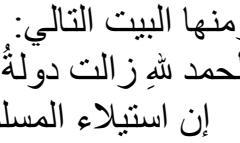

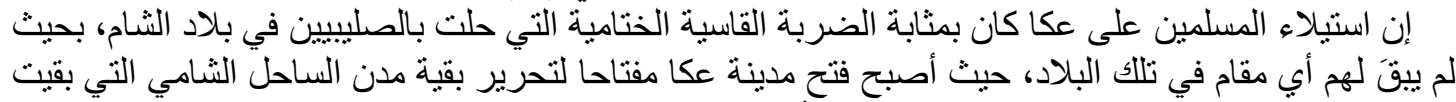

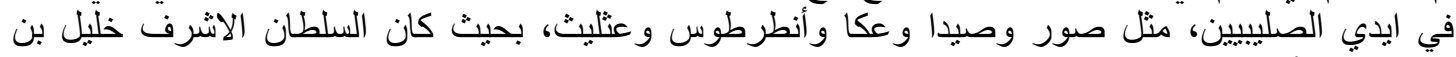

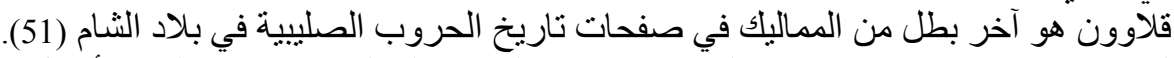

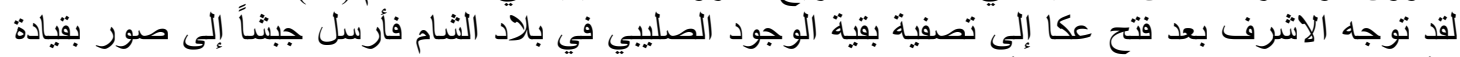

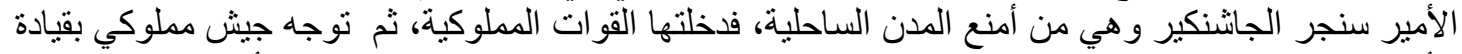

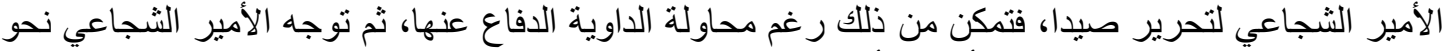

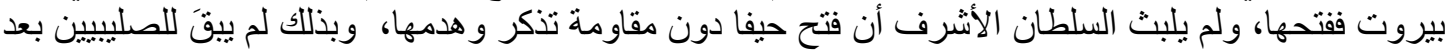

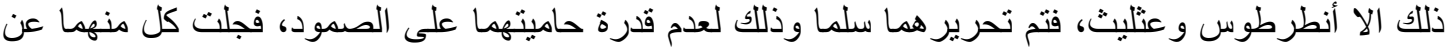

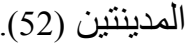
وبقيت جزيرة أرواد المقابلة للساحل الثرقي بأيديهم، فقد ظلوا يغيرون على السواحل بين الحين والآخر

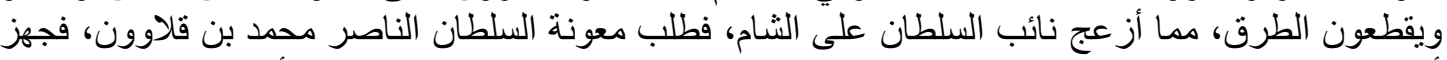

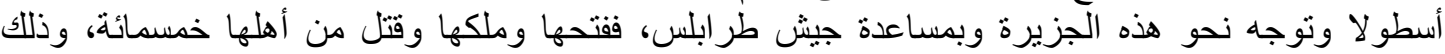

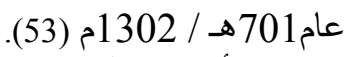

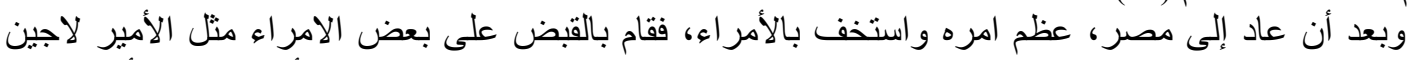

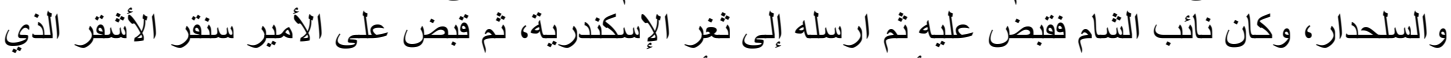

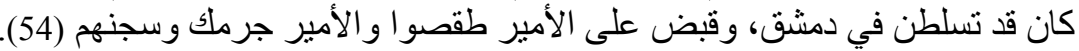

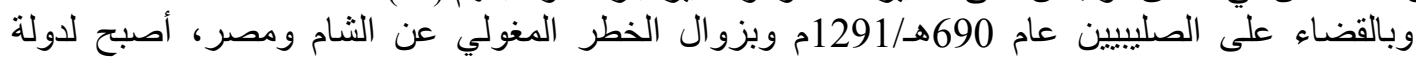

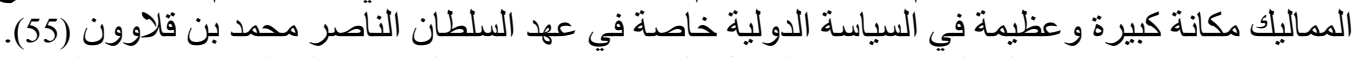

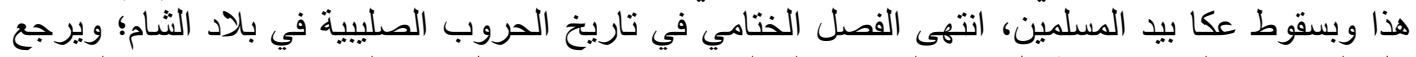

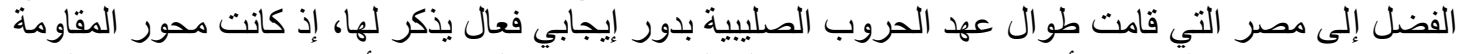

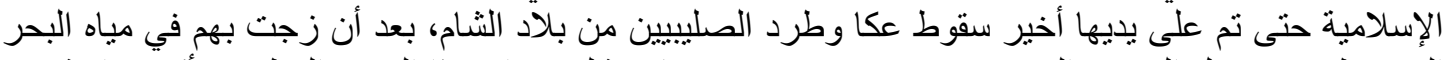

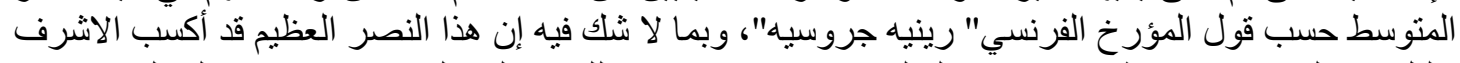

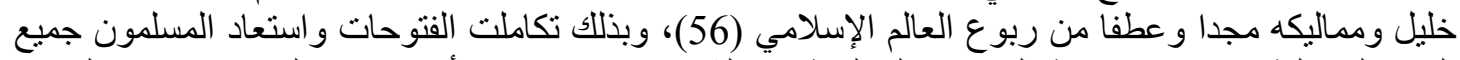

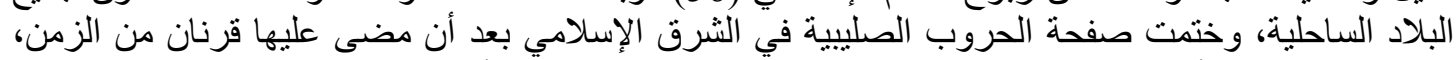

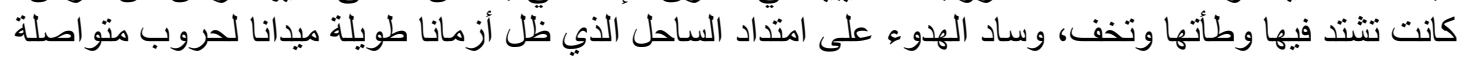

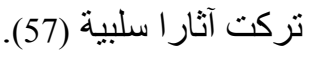

سادسا- وفاته:

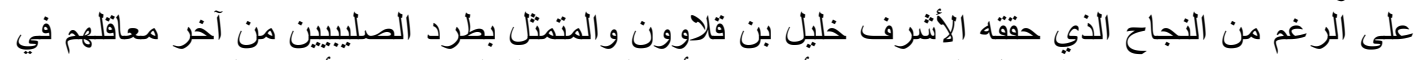

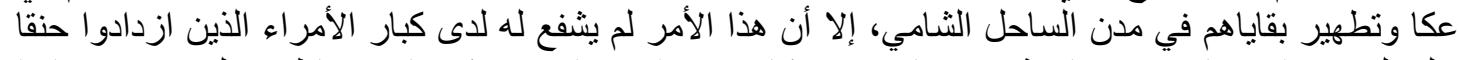

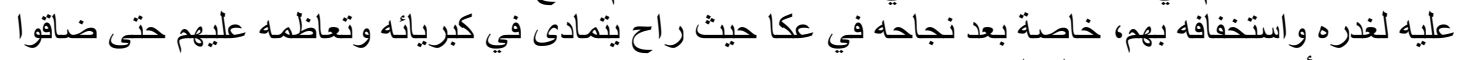

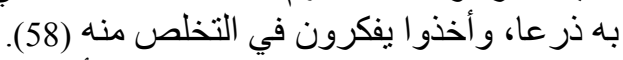

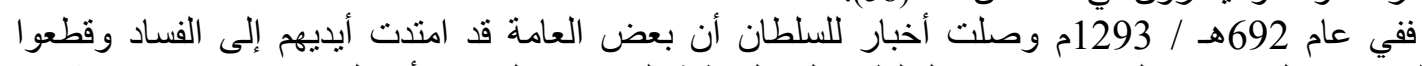

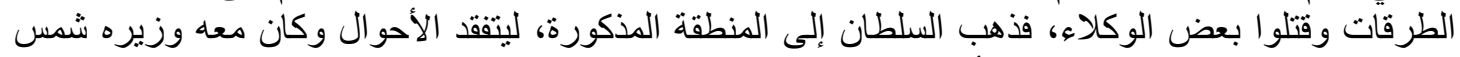

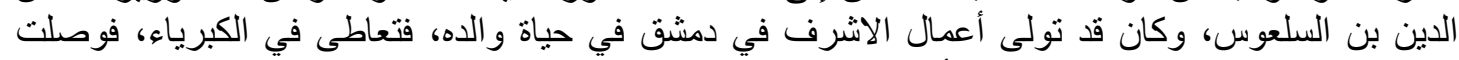

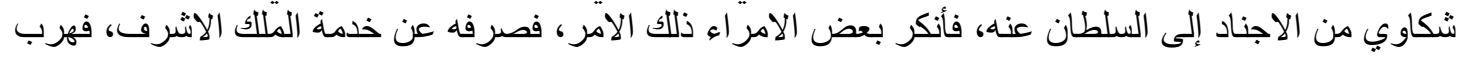

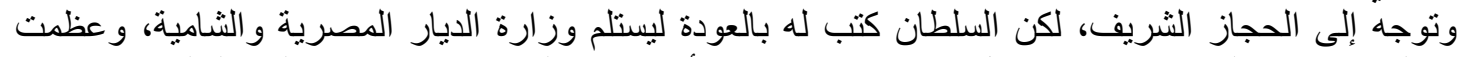

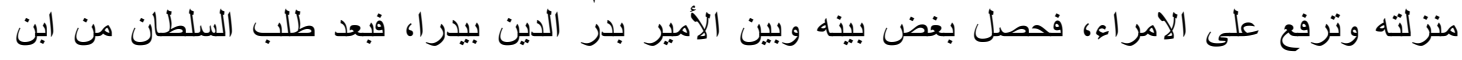




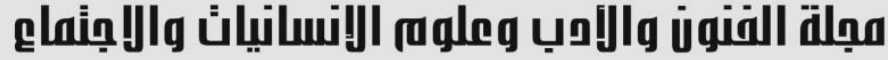

\author{
Journal of Arts, Literature, Humanities and Social Sciences \\ www.jalhss.com \\ Volume (53) June 2020 \\ العدد (53) يونيو 2020
}

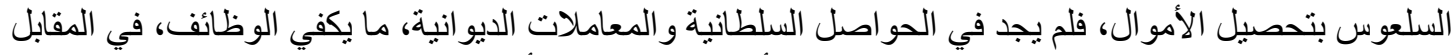

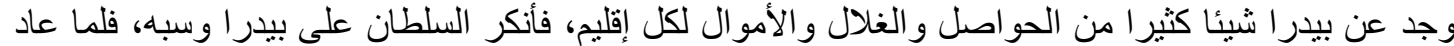

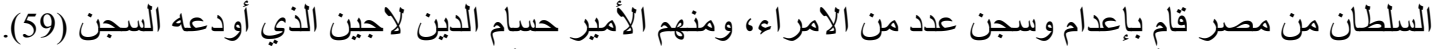

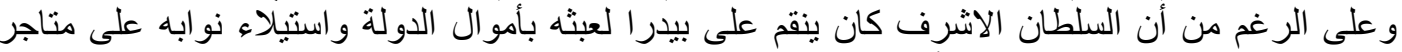

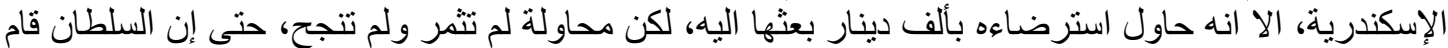

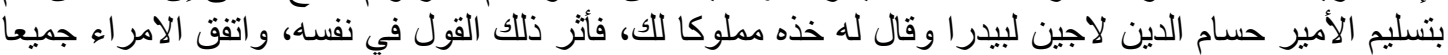

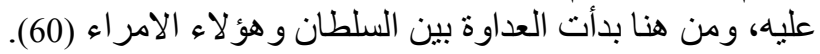

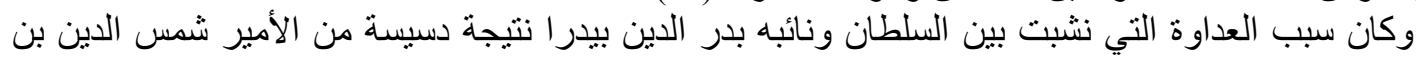

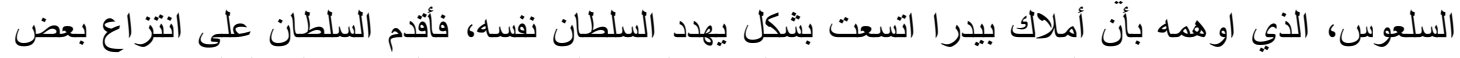

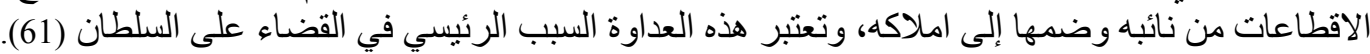

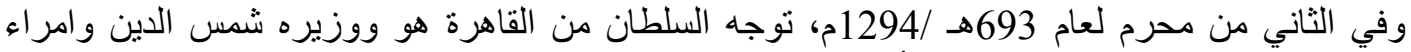

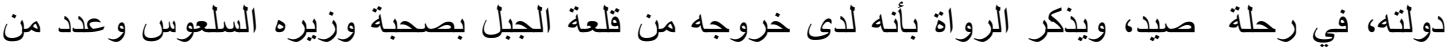

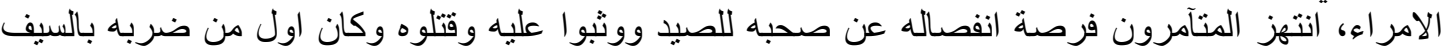

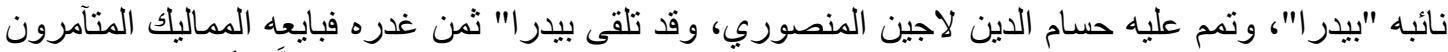

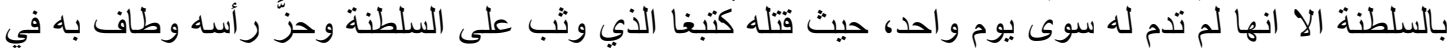

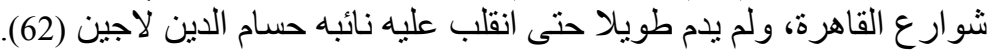

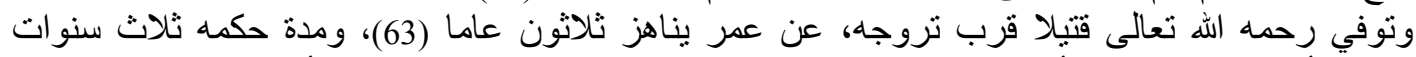

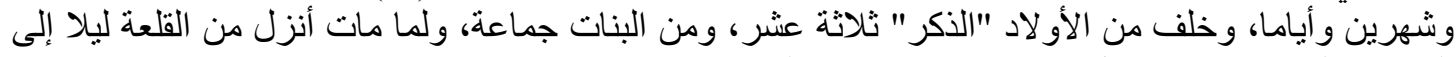

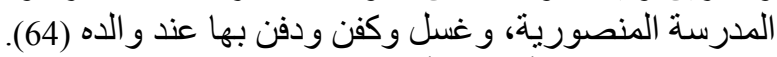

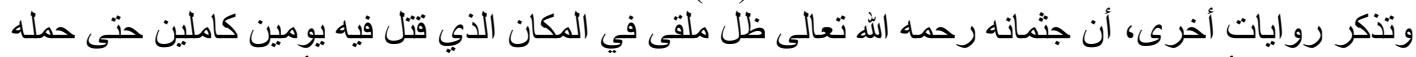

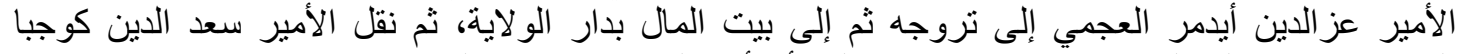

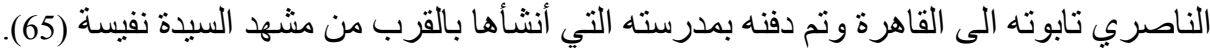

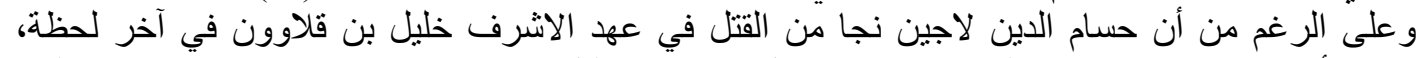

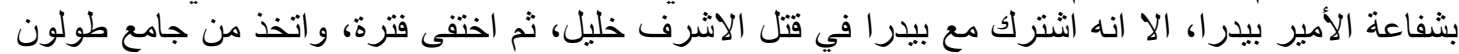

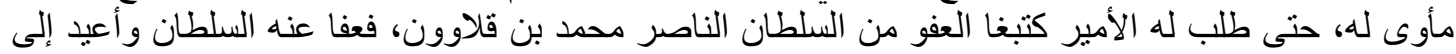

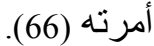

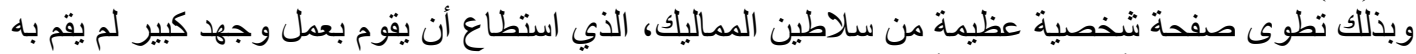

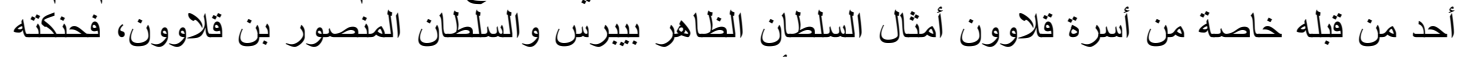

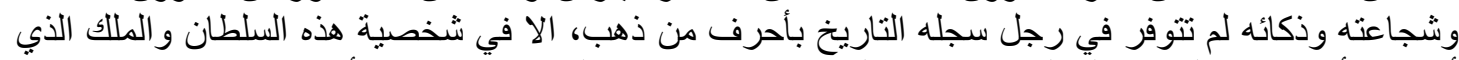

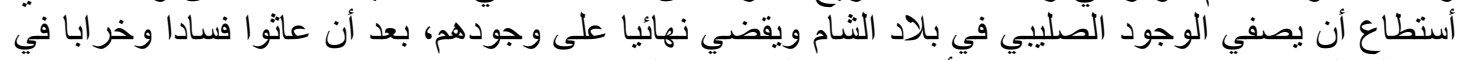
بلاد المسلمين، فمها تحدثنا لا نستطيع أن نفي هذه الثخصية التاريخية حقها.

القد خلصت الداتمة: الدة إلى مجمو عة من النتائج الآتية: 1- إن العقيدة الإسلامية الثابتة التي نشأ عليها الماليك، قد ساعدتهم في القضاء على الإلى الثار ات و الممالك الصليبية،

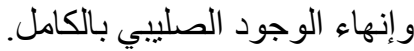

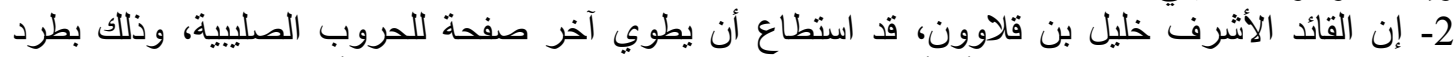

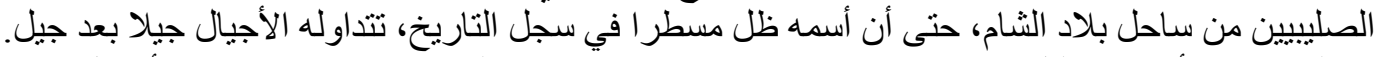

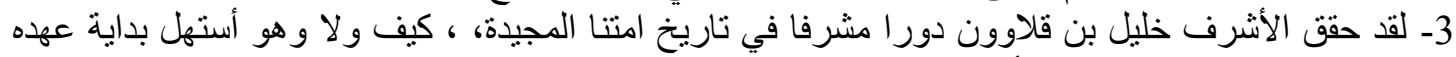

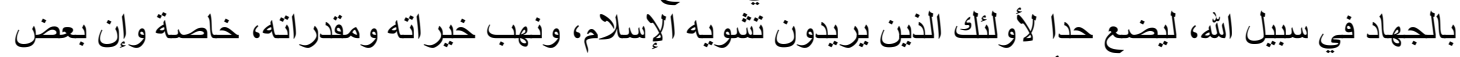

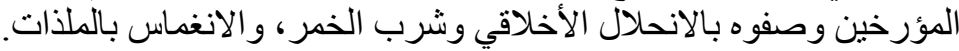
4- لقد امتازت شخصية الاشرف خليل بن قلاوون بالحالحكمة و الثنجاعة وقدرنه على اتخاذ القرار الحاسم وتحمل المسؤولية بعيدا عن الخوف او الجبن. 


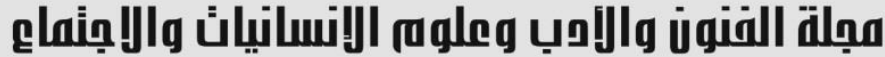

5- ينتمي الاشرف خليل بن قلاوون إلى بيت قلاوون والذي يتمتع بأهمية خاصة في تاريخ دولة سلاطين

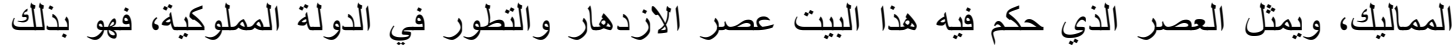
صاحب سيرة ونشأة بعيدة كل البعد عن التشويه او الحقد او الكراهية.

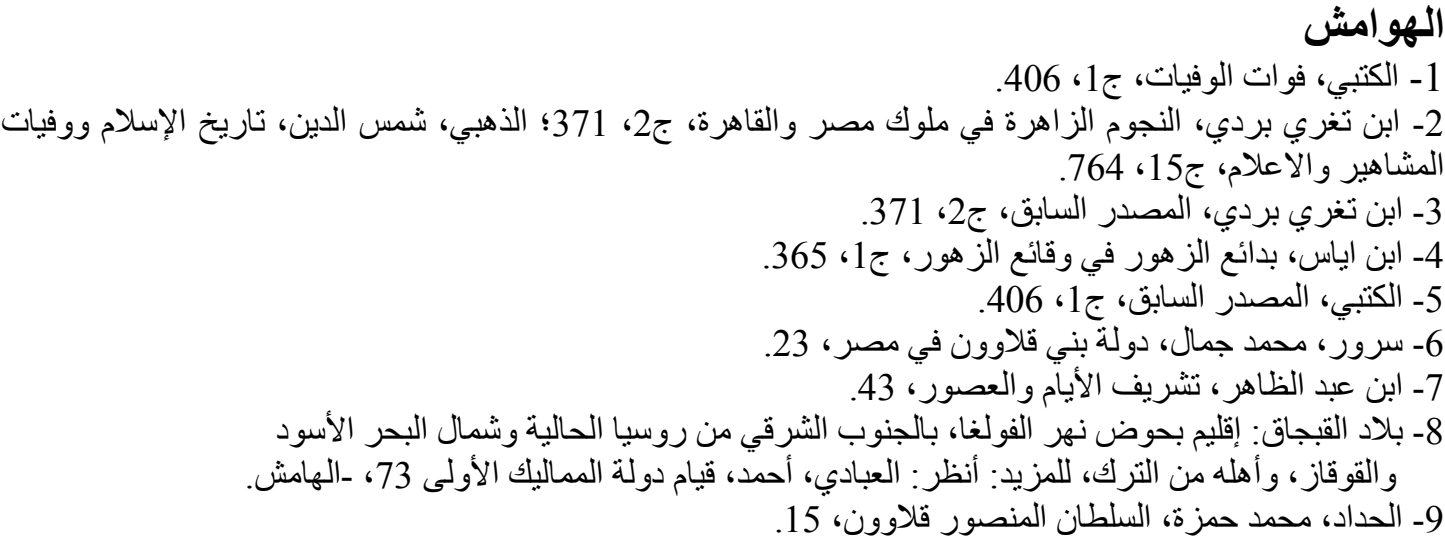

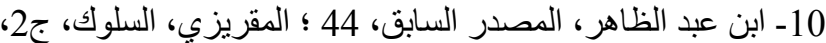

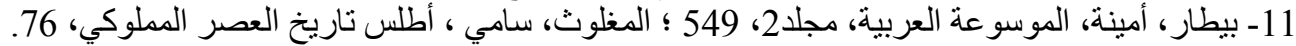
12- الكتبي، فوات الوفيات، ج1، 406-410 ؛ الذهبي، شمس الدين، تاريخ الإسلام ووفيات المشاهير و الاعلام، ج15،

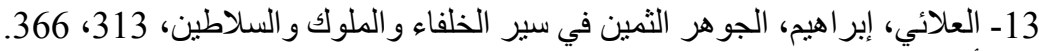

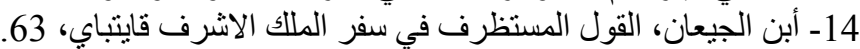

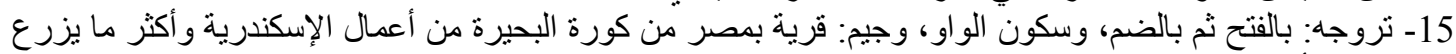

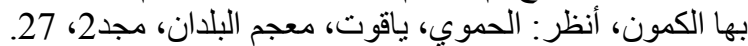

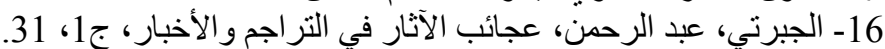

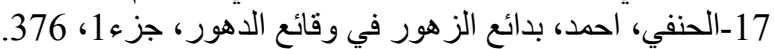

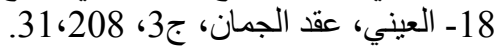

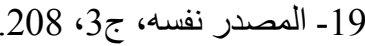

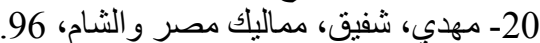

21- جندي، فلسطين، السلطان الاشرف خليل بن قلان الاوون وسياسته الداخلية والخارجية، 13-15 ؛ أنظر المققى الكبير ، ج3،

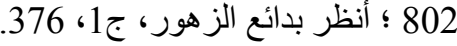

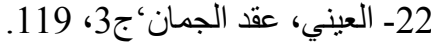

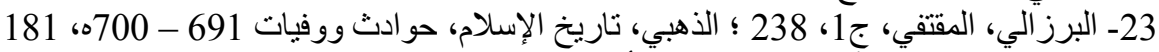

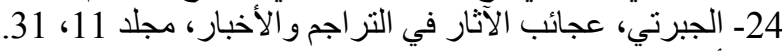

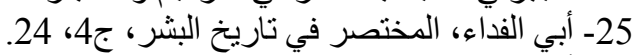

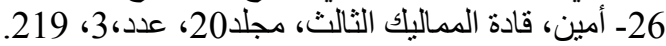

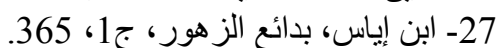
28 - قاسم، و وعلي، الأيوبيون و المماليك، اليك، 181.

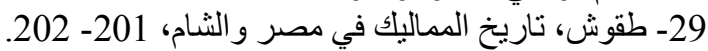

30 - موير ، تاريخ دولة المماليك في مصر ،

-13Templar of Tyre, p. 104/3

32- إسكندر، السلطان المملوكي الأشرف خليل بن قلاوون، 11 إليون 133

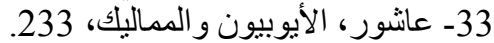

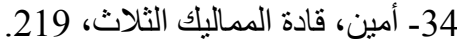

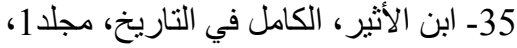

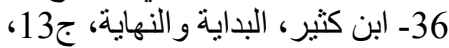
37- قاسم، الأيو بيون و المماليك، 181-182. 


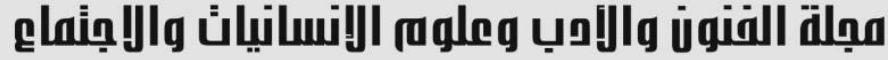

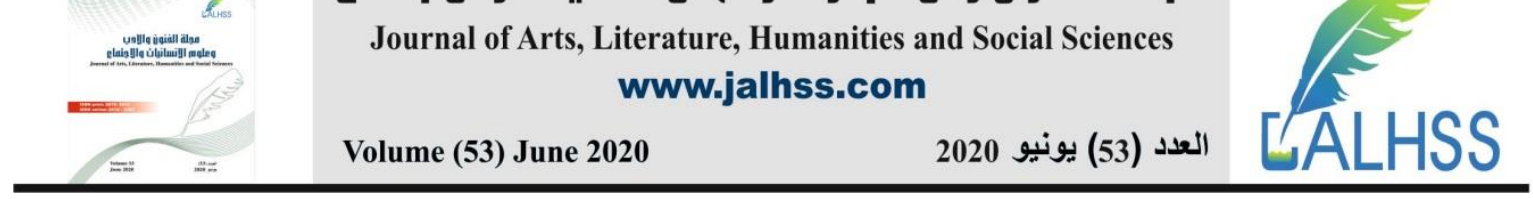

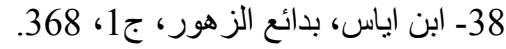

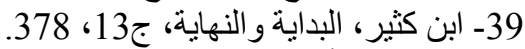

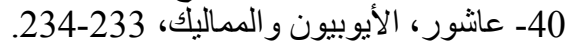

41 -4 عانثور، الحركة الصليبية،

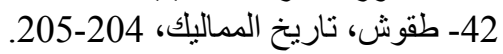

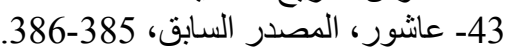

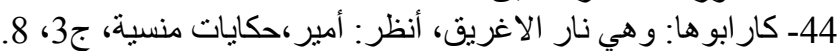

-45 Templar of Tyre, p.106-107/3

46- النقوب: جمع نقب وهو الخرق، والنقوب هي الفتحات التي يحدثها المنقبون في أسوار التحصينات، أنظر: عيسى،

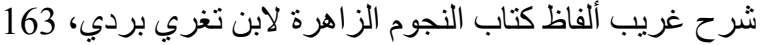

-47Templar of Tyre, p.106-107/3 48- الجنباز ، محمد، فتح عكا و السلطان خليل بن قلاوون، شبكة الالوكة الثقافية، 2019م.

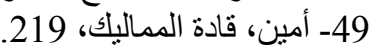

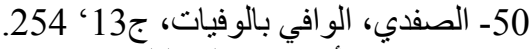

51 51 - 5اشور، الأيوبيون و المماليك، 234.

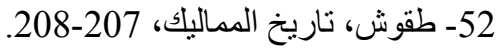

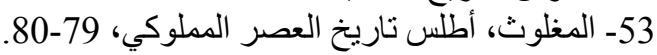

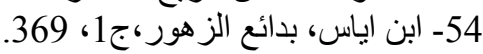

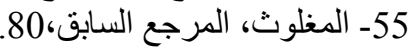

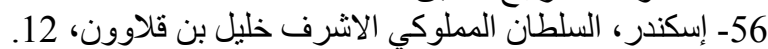
57 - 56 طقش، تاريخ المماليك، اليطن، 209

58- طقوس، تاريخ المماليك، 209 ـ 209 ؛ عاثشور، الأيو بيون و المماليك، 234.

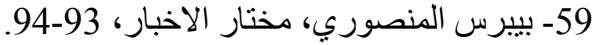

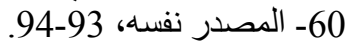

61 60 طقش، المرجع السابق، 209-2010-2010.

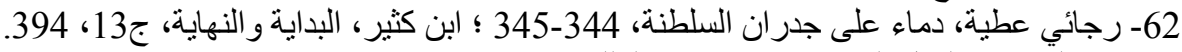

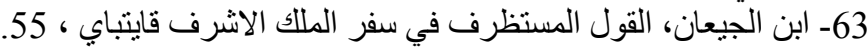

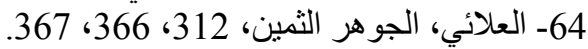

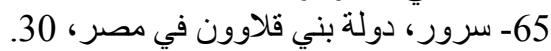

66- 65 الموسو عة المصرية: تاريخ مصر في القديمة، 1132.

\section{المصادر والمراجع إين}

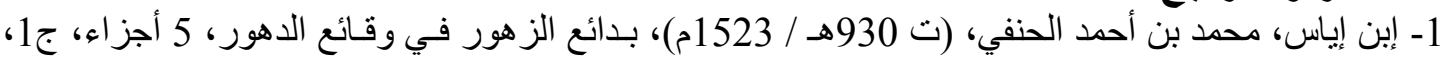

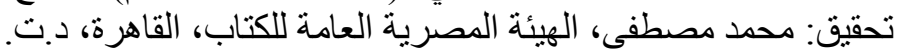

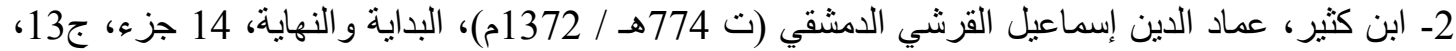

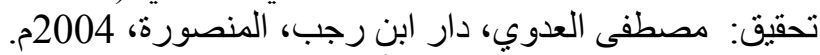

3- باقوت الحموي، شهاب الدين أبو عبداله ياقوت بل بن عبدالهابله الحموي، (ت 626هـ / 1228م)، معجم البلدان، 5

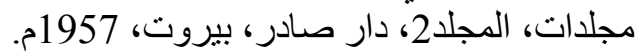

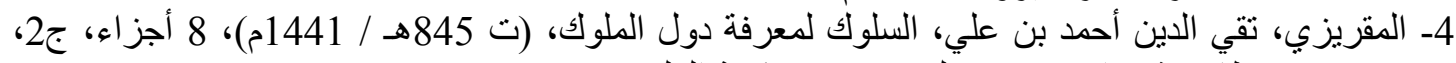

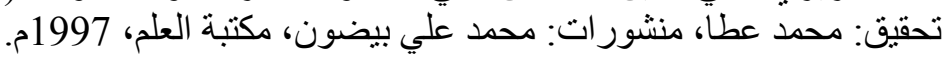

5- العيني، بدر الدين محمود، (ت 855هـ / 1451م) 1450)، عقد الجمان في تاريخ اهل الزمان الزمان، ج3، حوادث،(689 -

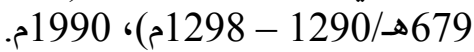

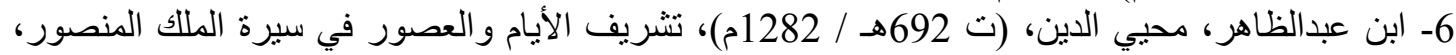

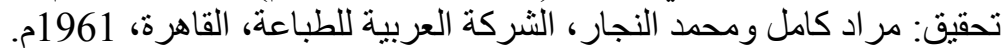

7- ابن شاكر الكتبي، محمد، (ت 764 هـ / 1361م)، فوات التئ الوفيات و الذيل عليها، 5 أجزاء، ج1، تحقيق: احسان عباس، دار الثقافة، بيروت، 1973 - 1974 - 1974م. 


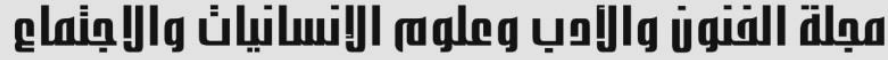

\author{
Journal of Arts, Literature, Humanities and Social Sciences \\ www.jalhss.com \\ Volume (53) June 2020 \\ العدد (53) يونيو 2020
}

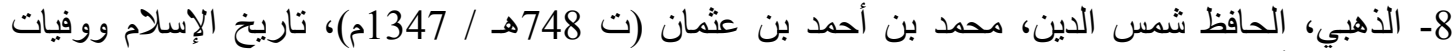

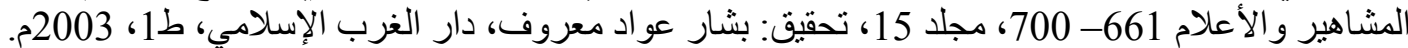

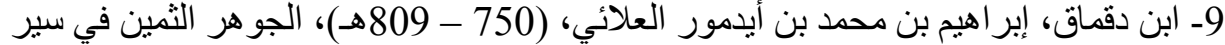

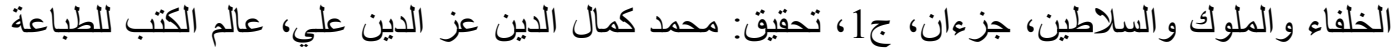

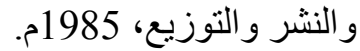
10- ابن تغري بردي، جمال الدين أبو المحاسن يوسف، (ت 874هـ / 1361م)، النجوم الزاهرة في ملوك مصر

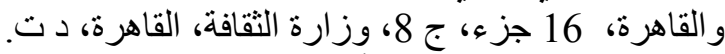

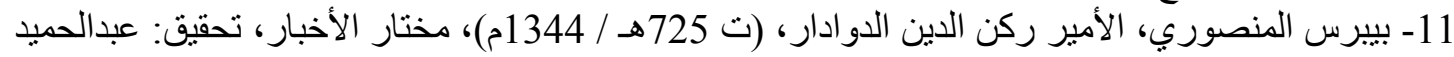

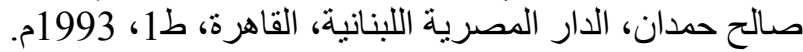

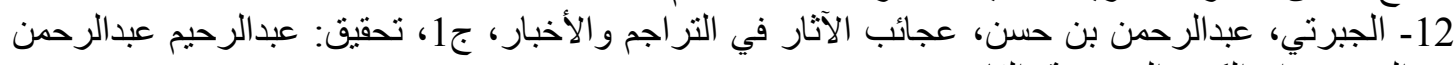
عبدالرحيم، دار الكتب المصرية، الرين، القاهرة، 1998م.

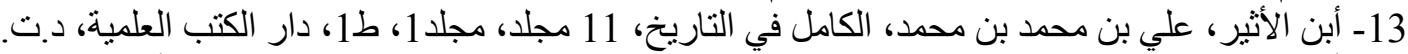

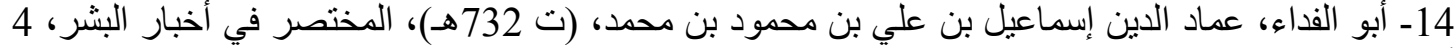

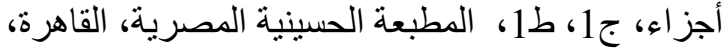

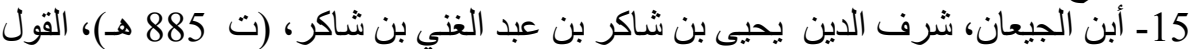

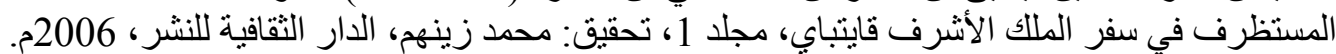

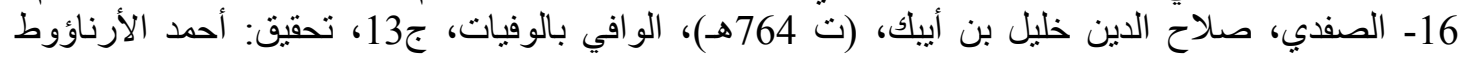

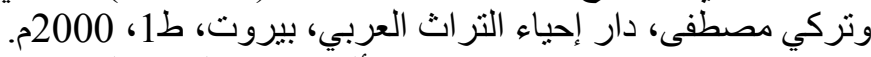

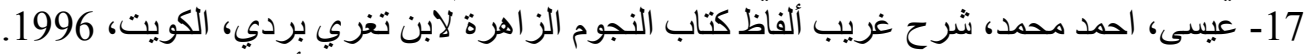

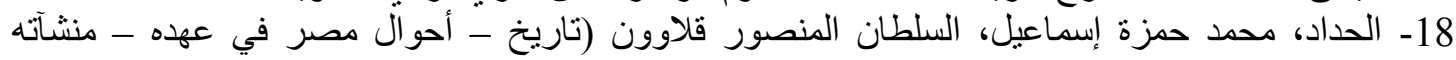

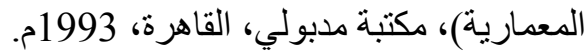

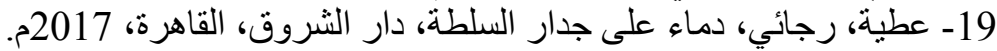

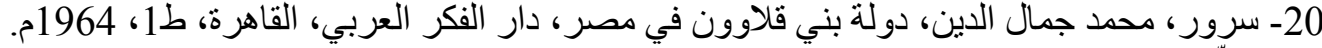

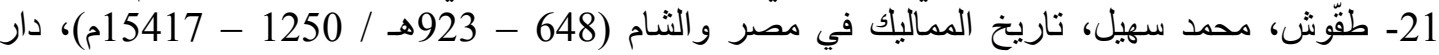

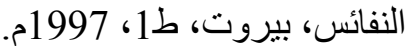

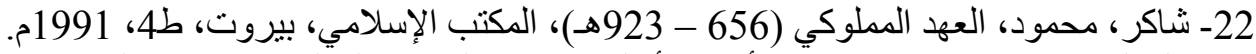
23- المغلوث، سامي بن عبداله بن أحمد، أطلس تاريخ العصر المملوكي، مكتبة العبيكان، الرياض، ط1، العيك، .0433 24- مجمو عة من العلماء و الباحثين، الموسو عة العربية العالمية، 30 مجلد، المجلد2، مؤسسة أعمال الموسوعة

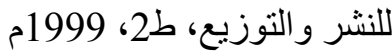
25- موير ، السير، وليم، ولتاريخ دولة الئة المماليك في مصر، ترجمة: محمود عابدين وسليم حسن، مكتبة مدبولي

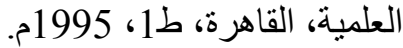

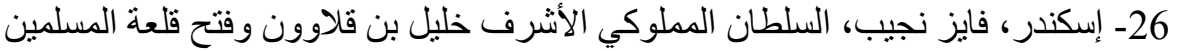

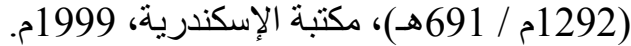

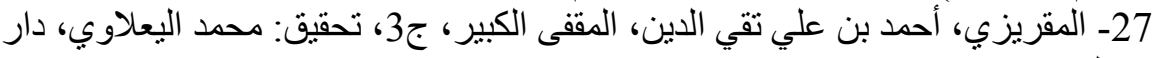

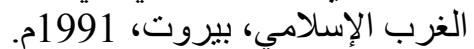

28- الجنباز ، محمد منير، فتح عكاو السلطان خليل بن قلاوون، شبكة الالوكة الثقافية، 2019م.،

من

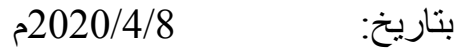

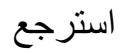

https://www.google.com/search?ei=KKKNXsyBLqqFhbIPm42miAk\&q= 29- عاثنور، سعيد عبدالفتاح، الحركة الصليبية ( صفحة مشرقة في تاريخ الجهاد الإسلامي في العصور

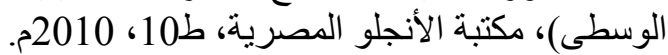

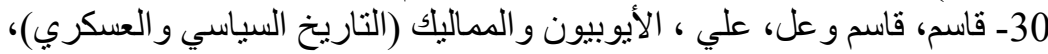
عين للار اسات و البحوث الإنسانية والاجتماعية، القاهرة، 2003م. 


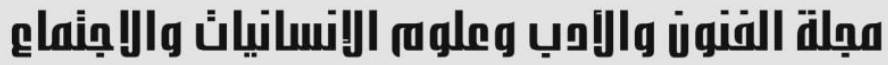

Journal of Arts, Literature, Humanities and Social Sciences www.jalhss.com

31- مهدي، شفيق، مماليك مصر و الثشام (نقودهم ونقوشهم ومسكو كاتهح و القابهم وسلاطينهم، 648 - 922هـ /

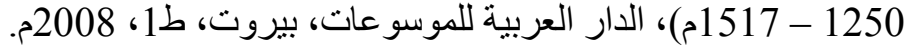

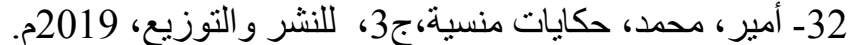

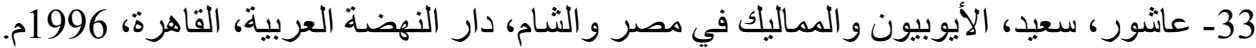

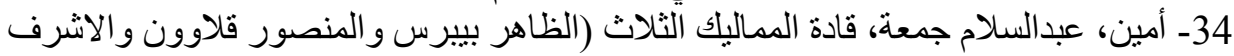

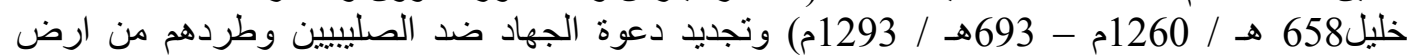

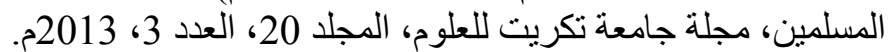

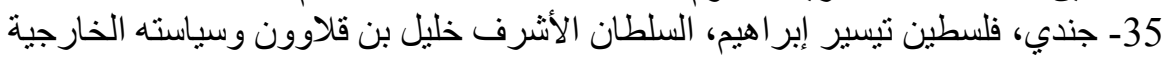

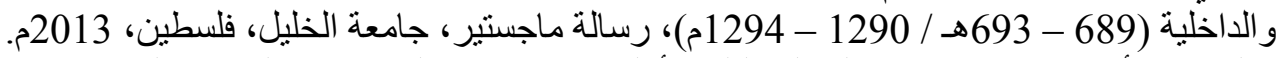

36- العبادي، أحمد مختار، قيام دولة المماليك الأولى في مصر والثام، دار النية النهضة العربة، بيروت، ط1،

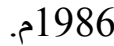

37- الموسوعة المصرية، تاريخ مصر القديمة وآثار ها: تاريخ آثار مصر الاسلامية، ISAM 90154 London (tarihsiz)

38- The Templar of Tyre, Chronicle (Getes des Chiprois), Published by

Crawford, Ashgate Publishing. Ltd, Cyprus 2003. ISBN 1-84014-618-4. 


\section{References}

1- Ibn Iyas, Muhammad ibn Ahmad al-Hanafi, (d. 930 AH / 1523 CE), Bada'a alZuhur in The Chronicle of Ages, 5 volumes, part 1, investigation: Muhammad Mustafa, the Egyptian General Book Authority, Cairo, D.T.

2- Ibn Katheer, Imad al-Din Ismail al-Qurashi al-Dimashqi (d. 774 AH / 1372 CE), The Beginning and the End, Part 14, Part 13, Investigation: Mustafa Al-Adawi, Ibn Rajab House, Mansourah, 2004AD.

3- Yaqout al-Hamwi, Shihab al-Din Abu Abdullah Yaqut bin Abdullah al-Hamwi (d. 626 AH / 1228AD), Glossary of Countries, 5 volumes, Volume 2, Dar Sader, Beirut, 1957 AD.

4- Al-Maqrizi, Taqi al-Din Ahmad bin Ali, Behavior to Know the Countries of the Kings, (T 845 AH / 1441 CE), 8 volumes, Part 2, investigation: Muhammad Atta, Publications: Muhammad Ali Baydun, Library of Knowledge, 1997 CE.

5- Al-Ainy, Badr Al-Din Mahmoud, (d. 855 AH / 1451 AD), Al-Joman contract on the history of the people of time, part 3, accidents, (689 - 679 AH / 1290 - 1298 AD), 1990 AD.

6- Ibn Abd al-Zahir, Muhy al-Din, (d. 692 AH / 1282AD), honoring days and eras in the biography of King Mansour, investigation: Murad Kamel and Muhammad alNajjar, the Arab Printing Company, Cairo, 1961.

7- Ibn Shaker Al-Ketbi, Muhammad, (d. 764 AH / 1361 AD), The Missing Deaths and the Tail on them, 5 parts, part 1, investigation: Ihssan Abbas, Dar Al Thaqafa, Beirut, 1973-1974.

8- Al-Thahabi, Al-Hafiz Shams Al-Din, Muhammad bin Ahmed bin Othman (d. 748 AH / 1347 AD), History of Islam and Celebrity Deaths and Media 661-700, Volume 15, Investigation: Bashar Awad Maarouf, Dar Al-Gharb Al-Islami, 1st edition, 2003AD.

9- Ibn Deqmaq, Ibrahim bin Muhammad bin Idmore Al-Ala'i, (750-809 AH), the precious essence of the biographies

Caliphs, Kings, and Sultans, two parts, part 1, investigation: Muhammad Kamal al-Din Izz al-Din Ali, book world for printing, publishing and distribution, 1985 AD. 10- Ibn Taghry Bardi, Jamal al-Din Abu Al-Mahasin Yusuf, (d. 874 AH / 1361 CE), the bright stars in the kings of Egypt and Cairo, 16 parts, c 8, the Ministry of Culture, Cairo, d.

11- Baybars Al-Mansouri, Prince Rukn Al-Din Al-Dawadar, (d. 725 AH / 1344 AD), Mukhtar Al-Akhbar, investigation: Abdel Hamid Saleh Hamdan, Egyptian-Lebanese House, Cairo, I 1, 1993 AD.

12- Al-Jabarti, Abd al-Rahman Ibn Hassan, the wonders of antiquities in biographies and news, part 1, investigation: Abd al-Rahim Abd al-Abd al-Abd al-Rahim, Dar alKutub al-Masria, Cairo, 1998

13- Ibn Al-Atheer, Ali bin Muhammad bin Muhammad, Al-Kamil in History, 11 volumes, Volume 1, 1st Edition, Dar Al-Kutub Al-Alami, Dr. 


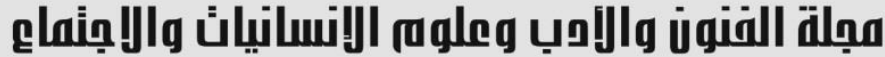

Journal of Arts, Literature, Humanities and Social Sciences

www.jalhss.com

14- Abu al-Fida, Imad al-Din Ismail bin Ali bin Mahmoud bin Muhammad, (d. 732 $\mathrm{AH}$ ), abbreviated in Akhbar al-Bishr, 4 volumes, c1, i1, al-Husayniyya Egyptian Printing Press, Cairo,

15- Ibn Al-Jiyan, Sharaf al-Din Yahya bin Shakir bin Abdul Ghani bin Shakir, (d. 885 AH), Al-Qul

The Prospective in the Book of King Ashraf Qaitbay, Volume 1, investigation: Muhammad Zaynham, Cultural Publishing House, 2006 AD.

16- Al-Safadi, Salah Al-Din Khalil bin Aybak, (d. 764 AH), Al-Wafi Balfiat, c. 13, investigation: Ahmed Al-Arnaout and Turki Mustafa, House of Arab Heritage Revival, Beirut, I 1, 2000 AD.

17- Easa, Ahmad Muhammad, Sharh Gharib Al-Fareh, Book of the Bright Stars by Ibn Tajri Bardi, Kuwait, 1996.

18- Al-Haddad, Muhammad Hamza Ismail, Sultan Al-Mansur Qalawun (History Conditions of Egypt during his reign - his architectural installations), Madbouly Library, Cairo, 1993 AD.

19- Attia, Rajae, blood on the wall of power, Dar El Shorouk, Cairo, 2017.

20- Sorour, Muhammad Jamal al-Din, the state of Bani Qalawun in Egypt, Dar al-Fikr al-Arabi, Cairo, i 1, 1964.

21- Taqosh, Muhammad Suhail, History of the Mamluks in Egypt and the Levant (648-923 AH / 1250-154717 CE), Dar Al-Nafees, Beirut, 1st edition, 1997AD.

22- Shaker, Mahmoud, the Mamluk Era (656-923 AH), Islamic Office, Beirut, 4th edition, $1991 \mathrm{AD}$.

23- Al-Maghlooth, Sami bin Abdullah bin Ahmed, Atlas of the History of the Mamluk Era, Obeikan Library, Riyadh, 1st edition, 433 AH.

24- A group of scholars and researchers, the International Arab Encyclopedia, 30 volumes, Volume 2, Encyclopedia Works Foundation for Publishing and Distribution, 2nd edition, 1999 AD

25- Muir, Al-Seer, William, History of the Mamluk State in Egypt, translation: Mahmoud Abdeen and Salim Hassan, Madbouly Scientific Library, Cairo, I 1, 1995.

26- Iskandar, Fayez Najib, the Mamluk Sultan, Ashraf Khalil bin Qalawun, and conquered the Muslim fortress

(1292 CE / 691 AH), Library of Alexandria, 1999 CE.

27- Al-Maqrizi, Ahmad ibn Ali Taqi al-Din, al-Muqfa al-Kabeer, part 3, investigation: Muhammad al-Ya`lawi, Dar

Islamic West, Beirut, 1991.

28- Al-Janbaz, Muhammad Munir, Fateh Akko and Sultan Khalil bin Qalawun, AlLuka Cultural Network, 2019 M.

$$
\text { Retrieved, on 4/8/2020 from }
$$

https://www.google.com/search?ei=KKKNXsyBLqqFhbIPm42miAk\&q=

29- Ashour, Saeed Abdel-Fattah, The Crusader Movement (A Bright Page in the

History of Islamic Jihad in the Middle Ages), The Anglo-Egyptian Library, 10th edition, 2010AD.

30- Qasim, Qasim Waal, Ali, the Ayyubids and the Mamluks (political and military history), 


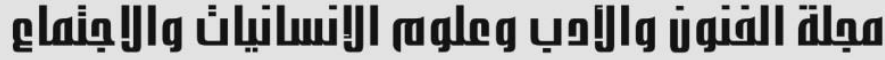 \\ Journal of Arts, Literature, Humanities and Social Sciences \\ www.jalhss.com \\ Volume (53) June 2020 \\ العدد (53) يونيو 2020}

Appointed for human and social studies and research, Cairo, 2003.

31- Mahdi, Shafiq, Mamluk of Egypt and the Levant (their money, their inscriptions, their coins, their nicknames, and their sultans, 648-922 AH / 1250-1517 CE), The Arab Encyclopedia, Beirut, 1st edition, 2008 AD.

32- Amir, Muhammad, Forgotten Tales, part 3, for publication and distribution, 2019 CE.

33- Ashour, Saeed, the Ayyubids and the Mamluks in Egypt and the Levant, Arab Renaissance House, Cairo, 1996.

34- Amin, Abd al-Salam Jum 'a, the leaders of the three Mamluks

Khalil $658 \mathrm{AH} / 1260 \mathrm{CE}-693 \mathrm{AH} / 1293 \mathrm{CE}$ ) and the renewal of the call for jihad against the Crusaders and their expulsion from Muslim land, Tikrit University Journal for Science, Volume 20, Issue 3, 2013AD.

35- Soldier, Palestine, Tayseer Ibrahim, Sultan Al-Ashraf Khalil bin Qalawun and his foreign policy

And Interior (689 - 693 AH / 1290 - 1294 CE), Master Thesis, University of Hebron, Palestine, 2013 AD.

36- Al-Abadi, Ahmed Mukhtar, The Establishment of the First Mamluk State in Egypt and the Levant, Dar Al-Nahda Al-Araba, Beirut, 1st edition, 1986 AD.

37- The Egyptian Encyclopedia, History and Archeology of Ancient Egypt: History of Islamic Archeology of Egypt, ISAM 90154. London (tarihsiz)

38- The Templar of Tire, Chronicle (Getes des Chiprois), published by Crawford, Ashgate Publishing. Ltd, Cyprus 2003. ISBN 1-84014-618-4. 